Board of Governors of the Federal Reserve System

International Finance Discussion Papers

Number 1109

June 2014

\title{
U.S. Unconventional Monetary Policy and Transmission to Emerging Market Economies
}

David Bowman Juan M. Londono Horacio Sapriza

Board of Governors of the Federal Reserve System

NOTE: International Finance Discussion Papers are preliminary materials circulated to stimulate discussion and critical comment. References to International Finance Discussion Papers (other than an acknowledgment that the writer has had access to unpublished material) should be cleared with the author or authors. Recent IFDPs are available on the Web at www.federalreserve.gov/pubs/ifdp/. This paper can be downloaded without charge from Social Science Research Network electronic library at www.ssrn.com. 


\title{
U.S. Unconventional Monetary Policy and Transmission to Emerging Market Economies*
}

\author{
David Bowman ${ }^{\dagger} \quad$ Juan M. Londono ${ }^{\ddagger} \quad$ Horacio Sapriza $^{\S}$ \\ This Version: June 23, 2014
}

\begin{abstract}
We investigate the effects of U.S. unconventional monetary policies on sovereign yields, foreign exchange rates, and stock prices in emerging market economies (EMEs), and we analyze how these effects depend on country-specific characteristics. We find that, although EME asset prices, mainly those of sovereign bonds, responded strongly to unconventional monetary policy announcements, these responses were not outsized with respect to a model that takes into account each country's time-varying vulnerability to U.S. interest rates affected by monetary policy shocks.
\end{abstract}

JEL Classification: F42, G15, E58.

Keywords: Unconventional monetary policy, Emerging markets, Large-scale asset purchase program, quantitative easing, Federal Reserve.

${ }^{*}$ We would like to thank John Ammer, Wenxin Du, Clara Vega, Chiara Scotti, and participants at the Federal Reserve Board Division of International Finance Workshop for helpful discussions. We would also like to thank Ben Scheiner for outstanding research assistance. The analysis and conclusions set forth are those of the authors and do not indicate concurrence by other members of the research staff or the Board of Governors.

†International Finance Division, Federal Reserve Board, Mail Stop 43, Washington DC 20551, USA; E-mail David.H.Bowman@frb.gov, Phone 202-452-2334.

†International Finance Division, Federal Reserve Board, Mail Stop 43, Washington DC 20551, USA; E-mail juan-miguel.londono-yarce@frb.gov, Phone 202-973-7478 (corresponding author).

§International Finance Division, Federal Reserve Board, Mail Stop 43, Washington DC 20551, USA; E-mail Horacio.Sapriza@frb.gov, Phone 202-452-2321. 


\section{Introduction}

Since the May 2013 Federal Open Market Committee (FOMC) announcement, which financial markets perceived as the beginning of the end of accommodative monetary policies in the United States, sovereign yields in emerging market economies (EMEs) have increased substantially and their currencies have depreciated notably. Converse movements were observed in 2008 when the FOMC announced its first large-scale asset purchase program (LSAP). At that time, the sovereign bond yields of these economies fell together with U.S. yields and stock prices were boosted.

The transmission of U.S. conventional and unconventional monetary policy to other assets in the United States and to international assets occurs through several channels, as has been documented in the literature. In the signaling channel, markets might interpret Federal Reserve (Fed) announcements as a signal of changes in future policy rates and the Fed's appraisal of the U.S. economy. Changes in the U.S. macroeconomic outlook affect global economic prospects, which might in turn affect other country's monetary policy decisions. A change in U.S. interest rates may also spark foreign currency depreciation, leading investors to expect foreign central banks to accommodate their monetary policies in response. In the portfolio-balance channel, changes in U.S. rates or the purchase of assets by the FED might encourage investors to shift their holdings of certain assets, including international assets. Finally, in the financial market channel, quantitative easing (QE) operations directly impact the functioning of financial markets and liquidity premia.

While there are a number of models and economic channels that can help to explain the transmission of U.S. monetary policy to foreign asset prices, a remaining key empirical question addressed in this paper is whether unconventional monetary policy announcements in the United States have had outsized effects above and beyond what the average correlation between EMEs and U.S. financial conditions would suggest. Moreover, there is little empirical evidence on what makes some EMEs more vulnerable than others to changes in U.S. monetary policy.

In this paper, we investigate the effect of U.S. unconventional monetary policy announcements on sovereign bond yields, foreign exchange rates, and stock prices in 17 EMEs. Our paper makes several empirical contributions to the literature. First, we use the method in Rigobon (2003) to identify the impact of monetary policy shocks on EME asset prices in a vector autoregressive model. We find that the effect of U.S. monetary policy shocks is significant, especially for local-currency sovereign yields, in many countries, but the magnitude and the persistence of the effect varies tremendously across countries. Second, we propose a panel-data model to investigate which country-specific variables drive the heterogeneity in the average response of EME asset prices to U.S. monetary policy, and we assess the quantitative importance of each country-specific variable. We find that the deterioration of a country's economic conditions significantly increases its vulnerability to changes in U.S. monetary policy, which we characterize using a set of financial variables. Finally, we compare the average effect of U.S. interest rates on EME asset prices implied by our model to the effect observed around the days of unconventional monetary policy announcements since 2008. We find that, except for Brazil and Singapore, the average observed effect is safely within or below the confidence intervals of the model-implied effects. This finding indicates that while the Fed's unconventional policies have had an impact on the EMEs, this impact has not necessarily been unusually different from the typical impact that changes in U.S. 
interest rates have had historically. We now describe our empirical strategy in more detail.

To identify monetary policy shocks in the United States and to estimate the impulseresponse function for each asset in each EME, we follow the method in Wright (2012). This method identifies the impact of policy shocks under the assumption that the volatility of these shocks is higher on the days when the Fed made key announcements about its unconventional monetary policies. The set of unconventional monetary policy announcements we employ is comprised of announcements related to the LSAPs and the maturity extension program (MEP) or "operation twist." We also include several FOMC announcements and speeches in 2013 that were perceived by investors as less accommodative, such as the May FOMC, or perceived as more accommodative, such as Chairman Bernanke's speech on July 10. We control for relevant monetary policy and macroeconomic announcements in each EME. We also test the robustness of our results by comparing them to a more simple event study on unconventional monetary policy announcements.

We find that monetary policy shocks have an effect on domestic interest rates, in line with the evidence in Rogers et al. (2013). We also find that U.S. monetary policy shocks have a significant effect on the yields of sovereign bonds of most EMEs in our sample. Moreover, the estimated effect of unconventional monetary policy shocks on the sovereign bond yields of some countries is even larger than the effect on U.S. sovereign yields. We document a similarity of heterogeneous responses in a simple set of regressions linking EME exchange rates and stock prices to general movements in U.S. interest rates.

To understand what drives the heterogeneous average responses of EME asset prices to U.S. financial conditions, we propose a univariate panel-data model to assess one by one how different country-specific characteristics affect the response of EME asset prices to changes in U.S. interest rates that are affected by U.S. monetary policy shocks. We find that several country-specific variables drive the vulnerability of EME asset prices to changes in U.S. interest rates. In particular, countries with high long-term interest rates, 5-year Credit Default Swaps (CDS) spreads, inflation rates, or current-account deficits, and with more vulnerable banking systems are more affected by changes in U.S. interest rates. Based on these results, we propose a multivariate panel-data model that accounts for each country's vulnerability to changes in U.S. interest rates. We compare the average response of EME sovereign yields to changes in U.S. sovereign yields implied by our model to the observed response to unconventional monetary policy announcements. We find that, except for Brazil and Singapore, the estimated response to unconventional monetary policies lies within the confidence intervals of the response implied by our panel-data model. This finding suggests that, for most EMEs, fluctuations in sovereign yields around unconventional monetary policy announcements are in line with the average response to changes in U.S. financial variables once we control for each country's time-varying vulnerability.

Our work draws from different strands of the literature on monetary policy and international finance. One strand of the literature explores the effect of monetary policy shocks on asset prices. Wright (2012) uses a structural VAR with daily data to identify the effects of monetary policy shocks on longer-term interest rates in the United States since 2008, when the U.S. monetary policy rate approached its zero lower bound. The VAR is identified using the assumption that monetary policy shocks are heteroskedastic. Specifically, the identification condition in Wright (2012) is that monetary policy shocks are relatively more volatile around U.S. monetary policy announcements. We extend the work of Wright (2012) to an international setting and to a larger set of assets. In particular, we identify 
monetary policy shocks in the United States and calculate impulse-response functions for each asset in each EME. We also deviate slightly from the identification condition in Wright (2012) and assume that monetary policy shocks have higher-than-average variance on days of unconventional monetary policy announcements, yet the variance of any other shock to the economy is constant throughout the sample. Also using a structural VAR approach, Bekaert, Hoerova, and Lo Duca (2012) argue that loose monetary policy reduces risk aversion and uncertainty. Bekaert, Hoerova, and Lo Duca (2012) use high frequency changes in the futures rate around FOMC announcements as a measure of monetary surprise. In particular, they use two alternative measures of monetary surprise: the difference between the average Fed funds rate in a given month and the one month futures rate on the last day of the previous month, as in Bernanke and Kuttner (2005), and, for the zero-lower-bound period, they consider the surprise measure in Wright (2012). Their paper employs a structural VAR with risk aversion, uncertainty, real interest rate, and the log-difference of industrial production, and they impose several restrictions on the system to be able to identify the shocks and impulse-response functions. However, their VAR is monthly, and thus not as suitable as daily frequency analysis for investigating short-run effects of unconventional monetary policy announcements.

Our work is also intimately related to the literature on monetary policy spillovers on international financial asset prices and capital flows. Bruno and Shin (2013) explore the impact of monetary policy on capital flows and risk taking by global banks using an extended VAR where they include a proxy for the leverage of global banks and the real effective exchange rate. Their study finds that the leverage of global banks and the VIX mediate how much contractionary monetary policy affects exchange rates. A recent study by Hausman and Wongswan (2011) looked at the effects of FOMC announcements on financial markets in 49 countries, finding that the cross-country variation in the effects of U.S. monetary policy is largely explained by the exchange rate regime - stock indexes and interest rates in countries with less flexible exchange regimes respond more to U.S. monetary policy surprises. Their paper also finds the variation to be strongly related to the percentage of each country's stock market capitalization. Our paper adds to this literature by comparing the effect of standard and unconventional monetary policies.

A number of recent studies have centered their attention on the effects of U.S. unconventional monetary policy measures. For instance, Krishnamurthy and Vissing-Jorgensen (2011) shed light on the channels through which QE affects interest rates by analyzing the differential impact of QE on a sample of interest rates. Ahmed and Zlate (2013) analyze the effects of QE on capital flows to EMEs, focusing on the actual asset purchases rather than on policy announcements. Fratzscher et al. (2012) also explore spillover effects of U.S. QE on foreign economies and, similar to Ahmed and Zlate (2013), they focus mostly on the actual purchases rather than on the announcements. They find that LSAP announcements had smaller effects than actual FED operations, suggesting that investors did not fully price in the information in the FED announcements or that actual operations had an unexpected component. In a related study for the United Kingdom, Joyce et al. (2011) explore how QE affected the gilt markets, and how the effect of QE spread more widely into other financial asset prices, such as equities, corporate debt, and the exchange rate. They argue that the most timely and clear way to observe the effect of $\mathrm{QE}$ on the economy is by looking at financial markets.

The remainder of the paper is organized as follows. In section 2 , we detail the sources 
and treatment of the data and we present summary statistics. In section 3 , we investigate the response of each asset in each EME to monetary policy shocks in the U.S. using impulseresponse functions and we discuss the results of our event study. In section 4, we first investigate one by one the determinants of the cross-country variation in the average response to U.S. monetary policy using a monthly panel-data setup. Second, we compare the observed responses of EME asset prices around unconventional monetary policy announcements to those implied by the panel-data model that accounts for the country-specific vulnerability determinants identified in the first step. Section 5 concludes.

\section{Data and Summary Statistics}

In this section, we introduce the data on sovereign bond yields, exchange rates, and headline stock indexes for 17 EMEs.

Our data sample runs from January 2006 to December 2013 and covers the following three asset classes: fixed-maturity 10-year sovereign bonds (in local currency), exchange rates with respect to the U.S. dollar, and headline stock indexes. ${ }^{1}$ We found enough available and reliable data for the three asset classes for 17 countries over the sample period. The countries included in our sample are Brazil, China, the Czech Republic, Hong Kong, Hungary, India, Indonesia, Korea, Malaysia, Mexico, the Philippines, Poland, Singapore, South Africa, Taiwan, Thailand, and Turkey. The data for asset prices are obtained from Bloomberg, except for the sovereign yields for Mexico and Brazil, which are calculated by De Pooter et al. (2013). We also consider EME aggregate indexes for each asset class. Specifically, for sovereign yields, we use the JP Morgan GBI-EM global composite index. ${ }^{2}$ The currency index is calculated as a weighted average of exchange rates with respect to the U.S. dollar, where the weights depend on trade volume with the United States. ${ }^{3}$. Finally, the stock market EME index considered is the MSCI emerging market index. To control for local macroeconomic surprises, we use Citigroup's economic surprise index for each country. ${ }^{4}$ Finally, we select a set of official announcements or speeches by the FED related to unconventional monetary policy. The set of unconventional monetary policy announcements is comprised of announcements related to the large-scale asset purchase programs (LSAPs) and the maturity extension program (MEP) or "operation twist." We also include several FOMC announcements and speeches in 2013 that were perceived by investors as less accommodative, such as the May, June, October, and December FOMC statements, or perceived as more accommodative, such as Ben Bernanke's speech on July 10.

Figure 1 shows time series for the aggregate index for EME sovereign yields, exchange rates with respect to the U.S. dollar, and stock prices in panels A, B, and C, respectively.

\footnotetext{
${ }^{1}$ We use 7 -year sovereign bonds for China and 5-year sovereign bonds for Turkey due to the lack of data for 10-year sovereign bonds for these countries.

${ }^{2}$ The average maturity of the sovereign bonds used to calculate the index ranges between 5 and 6 years for our sample. As far as we know, a fixed-maturity sovereign yield aggregate index is not available.

${ }^{3}$ The trade volume data are obtained from the IMF.

${ }^{4}$ Citigroup's surprise indexes are calculated using a set of country-specific surprises in key economic indicators and their impact on each country's exchange rate with respect to the U.S. dollar. The weight of each indicator's surprise is calculated according to "relevance to markets," defined as the immediate impact (using 30-minute windows around the release of each indicator) on exchange rates as described in detail in James and Kasikov (2008).
} 
EME sovereign yields followed U.S. sovereign yields on the way down after the first LSAP announcement in November 2008. Then, after the May and June FOMC announcements, which were perceived by markets as the beginning of the end of accommodative monetary policies, EME and U.S. sovereign yields increased together. Interestingly, EME sovereign yields fell back following the FED's announcements of a decrease in the pace of LSAPs (officially announced after the December FOMC meeting). The comovement between exchange rates (panel B) and stock prices (panel C) and U.S. sovereign yields is less clear. In any case, EME currencies appreciated on net with respect to the U.S. dollar between the first LSAP announcement and the first quarter of 2013, right before the May FOMC statement. Moreover, EME stock prices stopped falling after the first LSAP announcement and recovered most of their pre-crisis value by the end of our sample, although stock prices also fell moderately after the May FOMC announcement. While these aggregate indexes provide insightful information to understand the dynamics of EME asset prices around unconventional monetary policy announcements, the price fluctuations around these announcements vary considerably across assets and across countries, as we discuss below (and then again in section 3.3).

Table 1 reports summary statistics for one-day fluctuations in 10-year sovereign yields for each EME in basis points. The average fluctuation in sovereign yields is very small for all countries, ranging between -0.35 bps (Philippines) and $0.10 \mathrm{bps}$ (China). Indeed, the average fluctuation in the EME aggregate sovereign yields index is 0.02 bps. However, changes in yields are, with the exception of China and Taiwan, quite volatile. The aggregate index's volatility is 4.30, but changes in yields in countries such as Brazil (16.83), Indonesia (17.20), Mexico (16.96), and South Africa (22.26) display large volatilities. To illustrate the wide variations observed in sovereign yields over the period covered by our sample, we report the largest one-day fall in each country's yield and the corresponding date. As expected, countries where changes in yields are more volatile also experienced the largest one-day drops in our sample. For instance, South African yields fell 647 bps in May 2006, and Mexican yields fell 190 bps in April 2006. Interestingly, most of the largest drops in yields for all other countries occurred in the last quarter of 2008, around the announcement of the first LSAP by the FED. Similarly, we also report the largest one-day rise and the dates on which these events occurred. Again, yields in Brazil (260 bps in January 2007), Indonesia (403 bps in October 2008), Mexico (188 bps in April 2006), and South Africa (655 bps in May 2006) experienced the largest one-day rises in our sample. For some countries, the largest one-day rise in yields occurred just before the first LSAP announcement. As it is to be expected from these large one-day fluctuations observed, the distributions of sovereign yields fluctuations deviate considerably from the normal distribution. Specifically, excess kurtosis ranges between 6.37 (Hong Kong) and 772.34 (South Africa), and skewness ranges between -0.72 (India) and 5.39 (Indonesia).

Table 2 reports the same set of summary statistics for the daily fluctuation of the logarithm of the foreign exchange rate with respect to the U.S. dollar (i.e., a positive change corresponds to an appreciation of the U.S. dollar). The mean appreciation rate for all currencies in our sample is almost zero but appreciation rates vary considerably through time. In general, currencies of countries with highly volatile sovereign yields are more volatile, which is the case for the South African rand (1.16) and the Brazilian real (1.07). Other currencies, such as the Hungarian forint (1.10) and the Polish zloty (1.07), also display relatively high volatility. Many of the patterns observed in the dynamics of sovereign yields are also 
present in exchange rates. For instance, we observe some of the largest one-day depreciations with respect to the U.S. dollar right before the first LSAP announcement, and most of the largest one-day appreciations in the period following this announcement. Also, distributions of exchange rate movements tend to be fat tailed, with excess kurtosis ranging between 4.37 (Philippines) and 47.69 (Korea).

Table 3 reports summary statistics for the logarithm of the change in daily stock returns for EME headline stock indexes. ${ }^{5}$ The average daily fluctuations were very small for each EME stock market. On average, the aggregate index increased 2 basis points per day over the sample period. Stock returns volatility ranges between 0.82 (Malaysia) and 1.87 (Brazil). In line with the dynamics we observed in sovereign yields and exchange rates, most stock indexes in our sample experienced their worst daily performance right before the first LSAP announcement, with one-day drops as large as 16 percent in the Czech Republic (October 10, 2008), and their best one-day performance a couple of days later. As has been extensively documented in the literature, stock returns deviate significantly from the normal distribution, with excess kurtosis ranging between 5.96 (Taiwan) and 17.74 (Malaysia), and skewness ranging between -1.26 (Malaysia) and 0.14 (India).

\section{Impulse-response Functions to U.S. Monetary Policy Shocks}

In this section, we identify the impulse-response functions of each asset class in each country to U.S. monetary policy shocks. To obtain the response of each asset price to these shocks, we use the identification-through-heteroscedasticity method proposed by Rigobon and Sack (2003). This method has been used by Wright (2012) and Rogers et al. (2013) to identify monetary policy shocks between 2008 and 2012, when the U.S. policy rate was kept close to its zero lower bound. In the first part of this section, we describe the method briefly. In the second part, we show the results for the effect of U.S. monetary policy shocks on EME asset prices. In the third part, we test the robustness of our results by comparing them to a more simple event study.

\subsection{Methodology}

We assume that $Y_{t_{d}}$ is a vector of yields for 10-year and 2-year U.S. sovereign bonds and AAA-rated and high-yield corporate bonds. The vector of yields is augmented by the price of an asset from each one of the EMEs for day $t_{d}$ (sovereign bond yields, the log of the exchange rate, and the log of the stock index price). The dynamics of $Y_{t_{d}}$ follow a reduced 1-day lagged VAR representation

$$
A(1) Y_{t_{d}}=\mu+\epsilon_{t_{d}},
$$

\footnotetext{
${ }^{5}$ The following headline indexes are considered: Brazil, Ibovespa; China, Shanghai Composite; Czech Republic, PX; Hong Kong, Hang Seng; Hungary, Budapest Stock exchange; India, S\&P Bombay; Indonesia, Jakarta Islamic; Korea, Korea Composite; Malaysia, Kuala Lumpur Composite; Mexico, Bolsa IPC; The Philippines, Philippines Stock Exchange Composite; Poland, WIG; Singapore, STI; South Africa, FTSE/JSE All-share; Taiwan, Taiwan Capitalization Weighted; Thailand, Stock exchange of Thailand; Turkey, Istanbul 100 .
} 
where the reduced-form errors, $\epsilon_{t_{d}}$, can be related to a set of underlying structural shocks, $\eta_{t_{d}}$, including U.S. monetary policy shocks as follows:

$$
\epsilon_{t_{d}}=R \eta_{t_{d}}
$$

We identify the parameters in matrix $A(1)$ and vector $R$ assuming that the volatility of monetary policy shocks changes on the day of unconventional monetary policy announcements. ${ }^{6}$

The identification-through-heteroskedasticity method allows us to measure monetary policy shocks from their effects on U.S. sovereign and corporate interest rates and EME asset prices. As in Wright (2012), the monetary policy shock is normalized to lower 10-year U.S. yields by 25 basis points. The confidence intervals used to assess the significance of these effects on each asset in $Y_{t}$ are calculated using a bias-adjusted bootstrap. The bootstrap method to calculate confidence intervals requires the hypothesis of changes in the volatility of U.S. monetary policy shocks around unconventional announcements to be satisfied. ${ }^{7}$

\subsection{The effect of U.S. Monetary Policy Shocks on EME Asset Prices}

Figure 2 shows the effect of U.S. monetary policy shocks on EME sovereign yields for horizons between 0 , or immediate effect, and 250 business days for the aggregate index and for each country in our sample. Our results suggest that this effect is negative for most countries in our sample, in line with the effect on U.S. sovereign and corporate interest rates. ${ }^{8}$ The effect is significant for the aggregate index, Brazil, Hong Kong, Indonesia, Korea, Malaysia, Mexico, the Philippines, Poland, Singapore, and Thailand (borderline significant). However, there is substantial heterogeneity in terms of the horizon and the magnitude of the estimated effect of U.S. monetary policy shocks. In particular, monetary policy shocks seem to have mainly an immediate effect (significant between 0 and 100 days) on sovereign yields for Hong Kong, Mexico, Singapore, and Thailand. The effect becomes significant at the medium-term horizon (from 50 days and up to 150 days) for the remaining countries and for the aggregate index. In terms of magnitude, a monetary policy shock that lowers U.S. 10-year yields by 25 basis points lowers the aggregate index's yield by 14 basis points immediately, and this effect increases to 19 basis points after 200 business days. For countries such as Hong Kong (13 bps after roughly 45 days), Malaysia (20 bps, immediate effect), and Singapore (9 bps after 90 days) the effect of a U.S. monetary policy shock is moderate and considerably lower than the effect on U.S. 10-year sovereign yields. In contrast, for other countries, such as Brazil (the effect peaks at around $60 \mathrm{bps}$ ), Indonesia (the effect peaks at around $36 \mathrm{bps}$ ), Korea

\footnotetext{
${ }^{6}$ In section 3.2, we discuss the sensitivity of our results to an alternative specification, much closer to that of Wright (2012), where the volatility of monetary policy shocks changes not only around unconventional monetary policy announcements but also around all FOMC announcements in our sample period.

${ }^{7} \mathrm{~A}$ much more detailed description of the method used to estimate the parameters and their standard deviations can be found in Wright (2012).

${ }^{8}$ To avoid identification problems, we consider one asset at a time. Thus, the estimated effect of monetary policy shocks on U.S. interest rates changes every time we add an asset. However, the estimated patterns for U.S. interest rates are always negative and of a similar magnitude, in line with the results in Wright (2012) and Rogers, Scotti, and Wright (2013). Based on the effect of monetary policy shocks on U.S. interest rates, in section 4.1, we use changes in the yields of 10-year sovereign and high-yield corporate bonds as proxies for the interest rate and the risk channel of monetary policy, respectively
} 
(33 bps after 60 days), Mexico (peaks at around $30 \mathrm{bps),} \mathrm{the} \mathrm{Philippines} \mathrm{(the} \mathrm{effect} \mathrm{peaks}$ at $53 \mathrm{bps}$ ), Poland (27 bps), and Thailand (38 bps, immediate effect), the effect is larger. ${ }^{9}$

Figure 3 shows the effect on each country's exchange rate with respect to the U.S. dollar. To estimate this effect, we augment the U.S. yields vector in equation 1 with each country's sovereign yield and the logarithm of the exchange rate with respect to the U.S. dollar. ${ }^{10}$ The estimated effect for the aggregate currency index is negative. That is, a monetary policy shock that lowers U.S. yields is followed by an appreciation of EME currencies. However, this effect is very small - a shock that lowers U.S. yields by 25 basis points is followed by an immediate appreciation of 0.5 percent of a basket of EME currencies with respect to the U.S. dollar - and not significant. Also, the estimated effect is close to zero and statistically insignificant for all countries in our sample but Brazil, where the effect is positive and borderline significant. This evidence is somewhat counter to common perceptions. For instance, after the June 2013 FOMC announcement, U.S. and EME interest rates increased considerably while EME currencies mostly depreciated against the dollar. These discrepancies could be explained by several shortcomings in our technique. For instance, the linear nature of our model cannot take into account possible nonlinearities due, for instance, to the unwinding of carry-trade strategies. We also do not control for changes in each country's currency regime or their interventions in foreign exchange markets. ${ }^{11}$

Similarly, figure 4 shows the effect of U.S. monetary policy shocks on EME stock prices. Again, as for exchange rates, we add each country's sovereign yield and the logarithm of the price of the headline index to the vector of U.S. yields in equation 1 . We find that the effect of U.S. monetary policy shocks is positive only for some countries, which would suggest that a shock that lowers U.S. yields has a positive effect on stock prices. However, the estimated effect is statistically indistinguishable from 0 for all countries in our sample. These results suggest that only a few unconventional monetary policy announcements are linked to unusually large stock returns.

We estimate the effects of monetary policy shocks for several alternative specifications to assess the robustness of our results. First, we assume that the volatility of U.S. monetary policy shocks changes not only around unconventional monetary policy announcements but also around all FOMC announcements in our sample period. Second, we control for the VIX (S\&P 500 options-implied volatility) as a proxy for risk aversion as in Bekaert et al. (2012), and we also control for the U.S. as well as each country's surprise index. Finally, we assume a specification where the VAR in equation 3.1 has two lags. The results for these robustness tests are left unreported to save space, and are available from the authors upon request. Because the estimated effect is rarely significant for exchange rates and stock prices, we mainly discuss the results for the robustness tests for sovereign yields. When we assume that the volatility of monetary policy shocks changes on all Fed announcement dates, the

\footnotetext{
${ }^{9}$ For Turkey and South Africa, we reject the hypothesis that the volatility of monetary policy shocks changes around the announcements (identification condition), which generates bias-bootstrap confidence intervals that cannot be interpreted.

${ }^{10}$ Adding the domestic sovereign yield improves the identification of the impulse responses. Specifically, in unreported results, we show that the effects of U.S. monetary policy are still insignificant in a specification without sovereign yields. However, in such specification, the confidence intervals are much wider.

${ }^{11}$ As we show in section 4.1, the currency regime is an important determinant of the vulnerability of each country's currency exchange rate to changes in U.S. monetary policy, which is characterized by a set of financial variables.
} 
effect of U.S. monetary policy shocks on sovereign yields remains significant for the same countries in the benchmark setup except for Indonesia and Poland. Similarly, when we add the VIX or the U.S. surprise index, allowing for the volatility of monetary policy shocks to change only around unconventional monetary policy announcements, the significance of the effect remains robust for all countries except for Brazil. However, when we simultaneously add the U.S. and each country's surprise index, the magnitude of the estimated effect changes considerably, the confidence intervals increase substantially, and most of the significance of the effect disappears. The contrasting results for this last specification suggest that the country-specific surprise index might introduce noise instead of improving the identification of the effect of shocks. ${ }^{12}$ Finally, when we assume a two-day-lagged VAR, the effect is robust for all countries in the benchmark specification but Hong Kong. Interestingly, for this specification, the effect of U.S. monetary policy shocks become significant for South Africa.

In sum, we find that monetary policy shocks in the United States have a significant effect not only on U.S. interest rates but also on sovereign yields for most countries in our sample. We also find that this effect varies considerably across countries. However, the effects on exchange rates and stock prices are statistically insignificant for all countries in our sample.

\subsection{Event Study}

Although we believe that the identification assumptions underlying our VAR analysis are plausible, we conduct a robustness check by looking at a more simple event-study analysis around unconventional monetary policy announcements.

Tables 4, 5, and 6 report a summary of 2-day changes (from the day before to the day after the announcement) in sovereign yields, foreign exchange rates, and stock prices, respectively, around unconventional monetary policy announcements. ${ }^{13}$ After the first LSAP announcement on November 25, 2008, U.S. 10-year sovereign yields dropped 34.5 basis points. In fact, except for the January 28 announcement, reductions in U.S. yields after every announcement in the first set of LSAPs correspond to tail events. The EME aggregate sovereign yields index also fell after these first LSAP announcements (except for the January 28 announcement), although less than U.S. yields. For many individual countries, fluctuations in sovereign yields after some of these first LSAP announcements were highly statistically signficant based on standard errors calculated assuming a normal distribution. Similarly, around the first set of LSAP announcements, most EME currencies appreciated with respect to the U.S. dollar, and U.S. and EME stock-market prices increased in many countries, especially after the first announcement. In some cases, EME currency appreciations and stock returns around the first set of LSAP announcements were statistically significant, but the results suggest that

\footnotetext{
${ }^{12}$ Although this result could also suggest that the country-specific surprise indexes are highly correlated with the VIX, the lack of identification does not seem to be due to multicolinearity. On the one hand, the poor identification is not observed when in addition to the VIX we include the U.S. surprise index, which one would expect is even more correlated to the VIX than country-specific indexes. On the other hand, a specification where only each country's surprise index is included yields very similar results to the specification with U.S. and country-specific surprises.

${ }^{13}$ We report the results for the 2-day event study to account not only for the asynchronicity of the markets considered but also to account for the possibility of delayed responses. In any case, the results for the 1-day event study are pretty much robust in identifying unusual changes. The results for the 1-day event study are left unreported to save space, and are available from the authors upon request.
} 
not all of these first LSAP announcements had outsized effects on EME asset prices, and that there was substantial heterogeneity in the responses across countries.

Fluctuations in EME asset prices were much smaller around the second LSAP, third LSAP, and MEP announcements. Relatively few of these fluctuations were statistically significant and they display widespread heterogeneity across countries - often times, there are mixed positive and negative responses around the same event for different countries. However, there were larger and more uniform responses around the June 2013 FOMC announcement, when EME asset prices seemed to retrace some of their gains after the first LSAP. Specifically, sovereign yields in most EMEs rose after the May, October, December, and, especially, the June FOMC announcement and were statistically significant for several countries including Brazil, Malaysia, and Mexico. Similarly, EME currencies in most countries appreciated considerably and stock prices fell, in some cases by statistically significant amounts.

In sum, the event study corroborates our finding that EME yields in local currencies tend to experience large fluctuations around U.S. unconventional monetary policy announcements. However, while we see some large moves in exchange rates and stock prices for some countries around some announcements, the results are less uniform and often less statistically significant.

\section{EME Vulnerability and the Transmission of U.S. Mon- etary Policy}

In the previous section we provided evidence of substantial fluctuations in EME asset prices, especially for sovereign bonds, in response to U.S. unconventional monetary policy shocks. However, our evidence suggests that the response differs considerably across countries. In the first part of this section, we propose a panel-data setup to investigate the determinants of the cross-sectional variation in the response to U.S. monetary policy. Based on this analysis, in the second part of the section, we center our attention on EME sovereign yields and estimate a model that allows for time variation in each country's vulnerability to U.S. monetary policy based on the country's economic conditions. We compare the model-implied average response with that observed around U.S. unconventional monetary policy announcements to assess whether average observed responses are outsized with respect to our model, instead of outsized with respect to a normal distribution as in the event study in section 3.3.

\subsection{Determinants of Heterogeneous Reactions to Changes in U.S. Financial Variables}

To identify which characteristics drive the vulnerability of EME asset prices to changes in U.S. monetary policy, we propose the following monthly panel-data setup similar to the specification in Hausman and Wongswan (2011):

$$
\begin{aligned}
\Delta Y_{i, t_{m}}^{E M E}=\alpha_{i}+\left(\beta_{1}+\beta_{2} * X_{i, t_{m}-1}\right) * \Delta Y_{\text {sov }, t_{m}}^{U S}+\left(\gamma_{1}+\gamma_{2} * X_{i, t_{m}-1}\right) * \Delta Y_{h y, t_{m}}^{U S} & +\ldots \\
& +\mathbf{Z}_{t_{m}}+\epsilon_{i, t_{m}}
\end{aligned}
$$


where $\triangle Y_{i, t_{m}}^{E M E}$ is the monthly change in either the sovereign bond yields, the log of the exchange rate, or the log of the stock index price for each country $i$ in our sample. ${ }^{14} \Delta Y_{\text {sov, } t_{m}}^{U . S}$ and $\Delta Y_{h y, t_{m}}^{U . S .}$ are monthly changes in U.S. 10-year sovereign yields and high-yield bond spreads, respectively. Following the findings in section 3 and in Wright (2012) and Rogers et al. (2013) that U.S. monetary policy shocks have a significant effect on the yields of U.S. sovereign and corporate bonds, we use $Y_{\text {sov }}^{U . S}$. to characterize the interest rate channel of transmission of monetary policy in the United States at the zero lower bound, and the spread of high-yield U.S. bonds, $Y_{h y}^{\text {U.S. }}$, as a proxy for the effect of monetary policy on risk (risk channel). The specification in equation 2 can be seen as a monthly restricted version of the VAR used to identify the impulse response functions in section 3 (equation 3.1), where we allow for the response of each country's asset price to fluctuations in the U.S. interest rates that are affected by U.S. monetary policy to depend on the country's characteristics, $X_{i, t_{m}-1} \cdot{ }^{15}$. We also include a set of control variables, $\mathbf{Z}_{t_{m}}$, including the VIX, a commodity price index, and the return of the S\&P 500 index. ${ }^{16}$

The country-specific variables are classified into four groups. The first group is intended to characterize the country's macroeconomic and financial stability. The second group includes variables that measure the country's financial openness or its dependence on external financing. The third group contains variables related to each country's currency regime and measures of currency risk. Finally, the fourth group contains two variables intended to characterize the vulnerability of each country's banking sector.

Table 7 summarizes the results for the panel-data model specified in equation 2 for the fluctuations in all countries' sovereign yields. Our results suggest that countries perceived as riskier, proxied by their policy rate, CDS spread, sovereign yields, or interest rate differential, are significantly more vulnerable to fluctuations in U.S. sovereign and high-yield bond yields. Interestingly, these proxies for risk have the highest gains in R-squared of all country-specific variables considered. Surprisingly, GDP growth is the only macroeconomic stability indicator that significantly explains vulnerability to U.S. sovereign yields (debt to GDP, inflation, and the output gap do not). ${ }^{17}$ We also find that the current-account deficit is significant in explaining heterogeneous responses to fluctuations in U.S. high yield spreads - countries with higher deficits become more vulnerable to fluctuations in U.S. financial variables. Also, while the Chinn-Ito measure of financial openness is significant in explaining responses to U.S. yields, the ratio of total stock market capitalization to GDP and the ratio of exports to U.S. to GDP are significant in explaining the heterogeneous responses to U.S. high yield-bond spreads. The results for the currency-related variables suggest that

\footnotetext{
${ }^{14}$ We use monthly frequency because most country-specific variables are only available at the monthly or quarterly frequency. Country-specific variables that were only available at quarterly frequency were linearly interpolated.

${ }^{15}$ The country-specific characteristics are described in detail in appendix A

${ }^{16}$ Some of the control variables are highly correlated among each other and with U.S. yields and highyield bond spreads. Hence, to verify that our regressions are not affected by multicolinearity, we also test alternative specifications removing the VIX and the return of the S\&P 500. Our main results are almost unchanged for these specifications. Specifically, the variables that we find drive the heterogeneous reactions to changes in U.S. financial conditions are the same as for the benchmark specification.

${ }^{17}$ In unreported results, we found that other proxies for economic activity, such as nominal GDP growth, are also not significant. Moreover, we also tried to use all of our economic activity measures with additional lags to account for the lag of the announcement, but these variables still do not play a role in explaining heterogeneity in the responses or vulnerability.
} 
countries with soft-pegged currencies are less vulnerable, in contrast with the findings in Hausman and Wongswan (2011). Also, countries with higher currency-risk are more vulnerable to fluctuations in U.S. financial variables. Finally, we obtain coherent results with the two bank-vulnerability measures. That is, countries with more vulnerable banking sectors, proxied either by average expected default frequency or by credit category, are also more affected by changes in U.S. yields.

Table 8 summarizes the results for the panel-data model specified in equation 2 for the changes in EME appreciation rates. We find that the risk channel seems to play a more important role for appreciation rates than the interest-rate channel. In other words, the country-specific variables drive the responsiveness of exchange rates to the U.S. high-yield spread much more than to U.S. sovereign yields. For instance, the currencies of countries with higher interest and inflation rates and current-account deficits tend to depreciate more after an increase in U.S. high-yield spreads. Some of these variables also explain the heterogeneous responses to fluctuations in U.S. sovereign yields. Also, country-specific currency-related variables are significant in explaining what makes some currencies more vulnerable than others to fluctuations in U.S. financial variables. In particular, our results suggest that, in line with intuition, countries with soft-pegged currencies will depreciate less after an increase in U.S. yields. In contrast, currencies with higher carry-to-risk ratios or higher currencyoptions implied volatility will depreciate more.

Finally, table 9 summarizes the results for the panel-data setup for EME stock returns. Unsurprisingly, given the imprecise estimation of the effect of U.S. monetary policy on stock returns, the set of variables that play a significant role in explaining heterogeneous responses of EMEs' stock returns to U.S. financial variables is much smaller. This set of variables includes the GDP growth, the ratio of exports to the United States to GDP, the currency regime, and the average bank credit category.

In sum, our panel-data model identifies several variables that can help explain the vulnerability of EME asset prices to fluctuations in U.S. interest rates or in U.S. high-yield bond spreads. Because these variables can vary over time, this introduces the possibility of time-varying responses to fluctuations in U.S. financial conditions. This possibility implies that, as a country's economic environment deteriorates, we might expect asset prices in this country to become more vulnerable to changes in U.S. monetary policy. We explore this further in the next section.

\subsection{EME Vulnerability and EME Yields' Reaction to U.S. Mone- tary Policy}

In this section, we explore a multivariate setup to account for time-varying vulnerability of EME asset prices to fluctuations in U.S. financial variables significantly affected by monetary policy. This setup allows us to investigate whether the observed response of EME asset prices to U.S. unconventional monetary policy announcements is comparable to the average response implied by our model. We center our attention on EME sovereign yields as, in line with intuition, our evidence suggests a much closer link between changes in these yields and U.S. financial variables linked to monetary policy.

Table 10 shows the estimated coefficients associated with a subset of country-specific variables, $X_{i, t_{m}}$ in equation 2 . In specification 1 , we consider the interest rate differential 
with respect to the United States - the variable with the single-highest explanatory power for fluctuations in EME yields (table 7) - and the soft peg currency regime. In specification 2, we add the currency-options implied volatility to the interest rate differential. In specifications 3 to 5 , we consider principal components of the following variables: interest rate differential with respect to the U.S., GDP growth, and current account deficit to GDP. These variables satisfy three conditions. First, they have relatively high explanatory power for heterogeneous fluctuations in EME yields (see, table 7). Second, they are available for all countries in our sample (see table A). Finally, the variables are in different groups, that is, they describe different aspects of the country's economic environment. To make results comparable across all specifications, we force the first principal component to be positively correlated with the vulnerability of EME asset prices to fluctuations in U.S. financial variables. To do so, we force the principal component coefficients associated with each variable to be homogeneous across countries. Also, to facilitate the interpretation of the first principal component as a measure of vulnerability, we force the coefficients in the first principal component to have the same sign as the coefficients in table 7 . In other words, an increase in interest rate differential or current account deficit or a decrease in GDP would be related to an increase in a country's vulnerability.

The results from the multivariate panel-data setup suggest that there are little gains in adding the soft peg currency regime to the interest rate differential or to the first and second principal components. Specifically, the gains in explanatory power increase from 8.33 to 8.60 for the specification with interest rate differential, from 5.26 to 5.46 for the specification with the first principal component, and from 6.66 to 6.76 for the specification with the first and second principal component (not shown). ${ }^{18}$ Although the currency-options implied volatility is not significant in explaining the heterogeneous reactions to U.S. financial variables, specification 2 outperforms the model with the first principal component (the gain in R-squared for the model with currency IV is 6.20 compared to 5.26 for the model with the first principal component). Also, although there are some gains in adding the second principal component to the specification with only the first principal component (6.66 compared to 5.26), the gains in explanatory power are much higher when the interest rate differential is considered. In other words, the interest rate differential seems to summarize a large portion of information about each country's vulnerability to fluctuations in U.S. financial variables.

Figure 5 shows the average observed response of EME sovereign yields to changes in U.S. sovereign yields around unconventional monetary policy announcements. The response around each announcement is calculated using the 2-day changes calculated in the event study (see table 4). We compare each country's average observed response with the average response implied by specification 1 of our model (see table 10). The model-implied average response is calculated as $\widehat{\beta}_{1}+\widehat{\beta}_{2} * E\left(X_{i, t_{m}}\right)$ (see equation 2). Our results suggest that the average observed responses of EME sovereign yields to U.S. yields are safely within or below the confidence interval of the responses implied by the model, except for Brazil and Singapore.

The observed response of yields in Brazil is outsized (that is, above the $95 \%$ upper confidence interval), which is coherent with our previous evidence from the event study

\footnotetext{
${ }^{18}$ Adding the managed floating currency regime variable has almost no additional effect on the gains in explanatory power for EME sovereign yields.
} 
and impulse-response functions. In particular, we find that Brazilian yields experienced some of the largest drops around all LSAP announcements, and the immediate response to U.S. monetary policy shocks is considerably higher than the response of U.S. sovereign yields. Also, asset prices in Brazil are particularly sensitive to the unwinding of carry-trade strategies because the Brazilian real is a traditional carry-trade investment currency. These sensitivities can create nonlinear dynamics that cannot be accounted for in our model. In an attempt to account for a portion of the effect of carry-trade sensitivity, in figure 6, we show the model-implied responses for specification 2, the specification with currency-options implied volatility. We find that, although the average observed responses are still outsized for Brazil and Singapore, the model-implied response of Brazilian (and Turkish) yields increases from 0.68 to 0.98 . This increase in the effect would suggest that Brazilian yields are particularly affected by U.S. financial variables due to the higher-than-average currency-options implied volatility.

For Singapore, while the average reaction of sovereign yields to changes in U.S. yields implied by the panel-data setup is statistically insignificant, the observed reaction around unconventional announcements is around 0.5- Singapore yields increase around 50 basis points for every 100 basis points increase in U.S. sovereign yields.

To account for a portion of the potential effect of the asynchronicity of the markets, in figure 7, we compare the model-implied responses from specification 1 with the average observed responses between 1 and 2 days. The results are virtually unchanged. That is, the observed response of yields in Brazil and Singapore are still outsized from the point of view of the model, while all other yields' responses are safely within or below the model-implied responses. Nevertheless, the average observed response of yields in Brazil decreases to 1.91 (compared to 2.67 for the 2-day responses).

In sum, we find that the average observed response around unconventional announcements is safely within or below the 95 percent confidence interval for 15 of the 17 EMEs, indicating that, after adjusting for time-varying vulnerability, the actual responses of most EME yields to U.S. unconventional monetary policy are not significantly different from the responses implied by our model. Furthermore, it's comforting to see that our model does not seem to systematically under- or over-estimate the average observed response around unconventional announcements.

\section{Conclusion}

As investors perceived the May and June 2013 FOMC announcements as less accommodative, U.S. Treasury yields rose considerably after a long period of relatively low interest rates. Yields of sovereign bonds in emerging markets also rose over the period, in some cases even more than they did in the United States. At the same time, the currencies of most emerging market economies depreciated substantially against the U.S. dollar and stock prices dropped in the first half of 2013. These fluctuations in EME asset prices have raised several questions about the potential impact of U.S. monetary policy decisions on foreign financial markets, especially in the EMEs. In this paper, we investigate the effect of U.S. monetary policy on EME asset prices, and we identify the country-specific characteristics that drive the countries' vulnerability to changes in U.S. monetary policy, which is characterized by 10year sovereign yields, to explain the interest rate channel, and high-yield spreads, to explain 
the risk channel.

We find that EME asset prices, especially sovereign yields in local currency, experienced large fluctuations around unconventional monetary policy announcements by the FED. In particular, asset prices in several EMEs experienced tail-event fluctuations around the dates of the first LSAP announcement, and then again around the June 2013 FOMC. We show that these large fluctuations in EME asset prices are in line with the estimated effects of U.S. monetary policy shocks. Specifically, we find that U.S. monetary policy shocks that lower U.S. sovereign yields also lower sovereign yields in most EMEs. In some cases, the effect on EME sovereign yields is larger than the effect on U.S. sovereign yields, and is clearly significant and persistent. We also find that several country-specific variables drive the vulnerability of countries to changes in U.S. monetary policy, characterized by sovereign yields and high-yield bond spreads. In particular, countries with high interest rates, CDS spreads, inflation rates, or current-account deficits and those with more-vulnerable banking systems seem to become more affected by changes in U.S. financial variables. Finally, we propose a model to account for each country's vulnerability to fluctuations in U.S. sovereign and corporate interest rates, and find that, for almost all EMEs, the effect of U.S. financial variables around unconventional monetary policy announcements is within or below the confidence interval of the effect implied by our model. This evidence suggests that U.S. unconventional monetary policies might not have had outsized effects on EME asset prices once each country's time-varying vulnerability has been taken into account. In other words, our evidence suggests that, as an EME's financial or macroeconomic conditions deteriorate, unconventional monetary policies might have unexpected, and sometimes unwelcome, effects on domestic asset prices.

A quantitative assessment of the importance of the different channels through which monetary policy decisions in the U.S. and other advanced countries affect asset prices in emerging market economies would be valuable but is outside the scope of this paper and the subject of a related, yet separate, ongoing research project. 


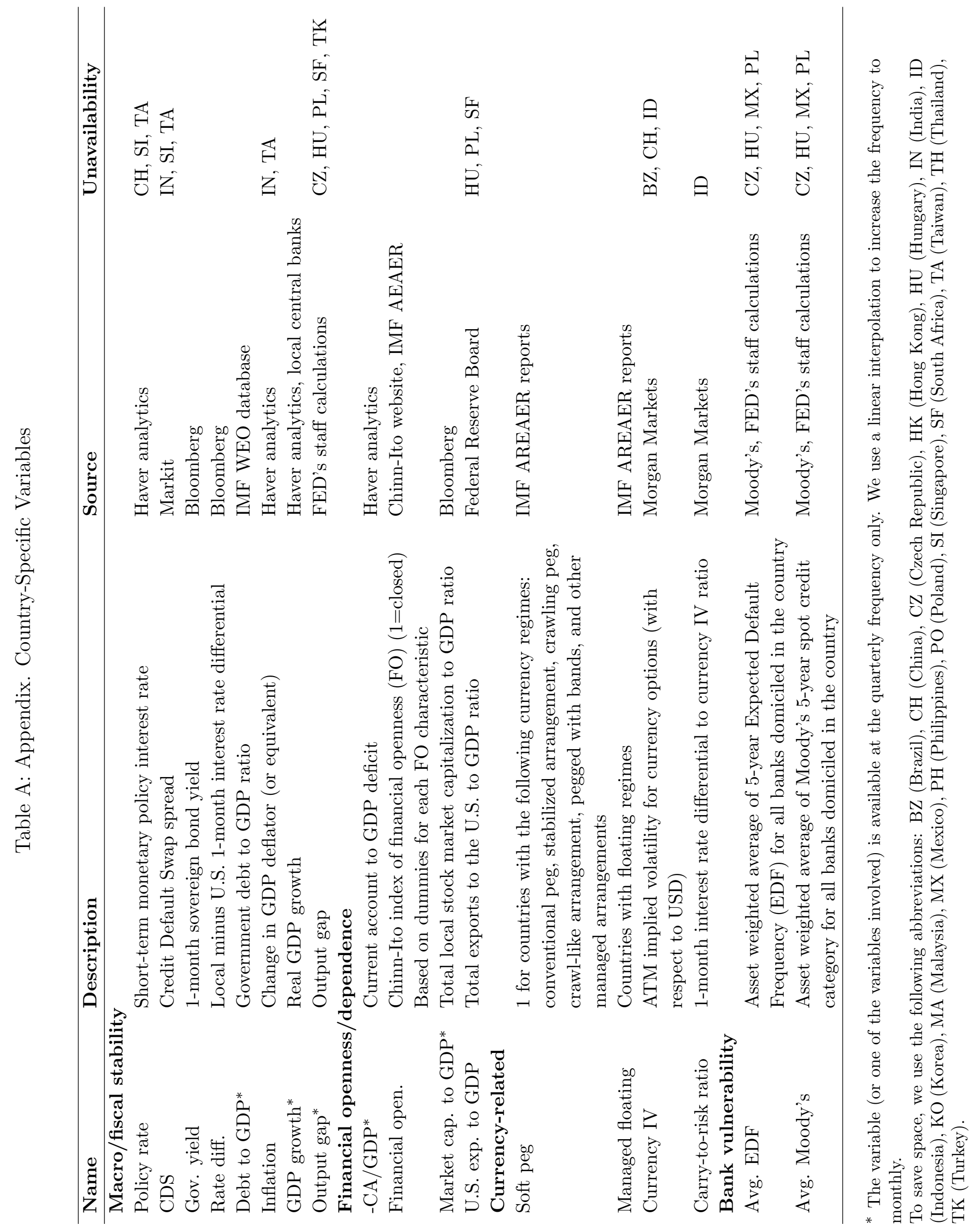




\section{References}

Ahmed, S. and A. Zlate (2013). Capital flows to emerging market economies: a brave new world. Federal Reserve Board, IFDP 1081.

Bekaert, G., M. Hoerova, and M. Lo Duca (2012). Risk, uncertainty and monetary policy. Working paper, Columbia University.

Bernanke, B. and K. Kuttner (2005). What explains the stock market's reaction to Federal Reserve Policy? Journal of Finance 60(3), 1221-1257.

Bruno, V. and H. Shin (2013). Capital flows and the risk-taking channel of monetary policy. Working paper, Princeton University.

De Pooter, M., P. Robitaille, I. Walker, and M. Zdinak (2013). Are long-term inflation expectations well-anchored in Brazil, Chile and Mexico. Working paper, Federal Reserve Board.

Fratzscher, M., M. Lo Duca, and R. Straub (2012). A global monetary tsunami? On the spillovers of U.S. quantitative easing. CEPR Working paper 9195.

Hausman, J. and J. Wongswan (2011). Global asset prices and FOMC announcements. Journal of International Money and Finance 30(3), 547-571.

James, J. and K. Kasikov (2008). Impact of economic data surprises on exchange rates in the inter-dealer market. Quantitative Finance 8(1), 5-15.

Joyce, M. A. S., A. Lasaosa, I. Stevens, and M. Tong (2011). The Financial Market Impact of Quantitative Easing in the United Kingdom. International Journal of Central Banking 7(3), 113-161.

Krishnamurthy, A. and A. Vissing-Jorgensen (2011). The Effects of Quantitative Easing on Interest Rates: Channels and Implications for Policy. Brookings Papers on Economic Activity, 215-287.

Rigobon, R. (2003). Identification through heteroskedasticity. Review of Economics and Statistics 31(), 777-792.

Rigobon, R. and B. Sack (2003). Measuring the reaction of monetary policy to the stock market. Quarterly Journal of Economics 118(2), 639-669. 
Rogers, J., C. Scotti, and J. Wright (2013). Evaluating Asset-Market Effects of Unconventional Monetary Policy: A Cross-Country Comparison. Federal Reserve Board working paper.

Wright, J. H. (2012). What does monetary policy do to long-term interest rates at the zero lower bound? Economic Journal 122(564), F447-F466. 


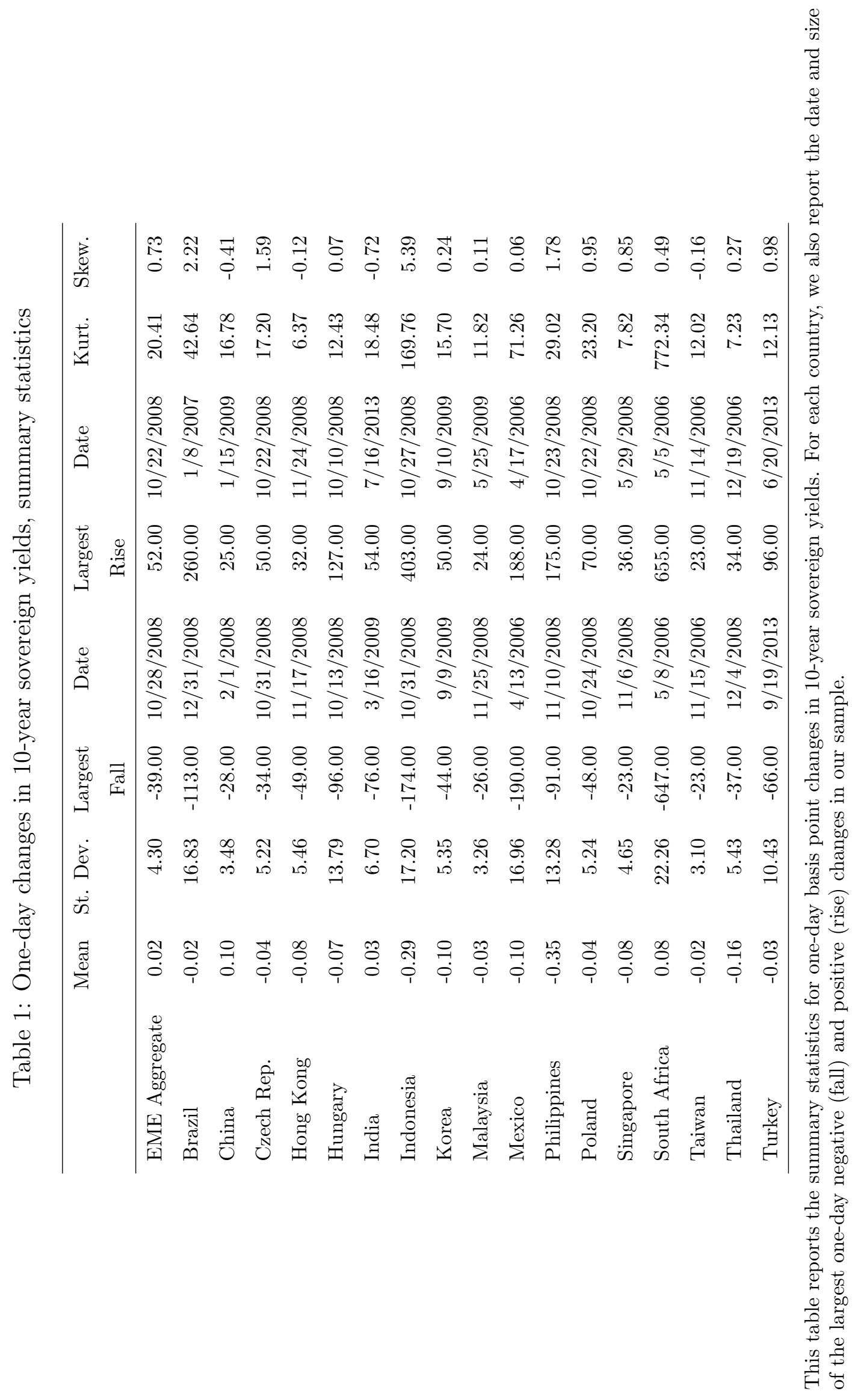




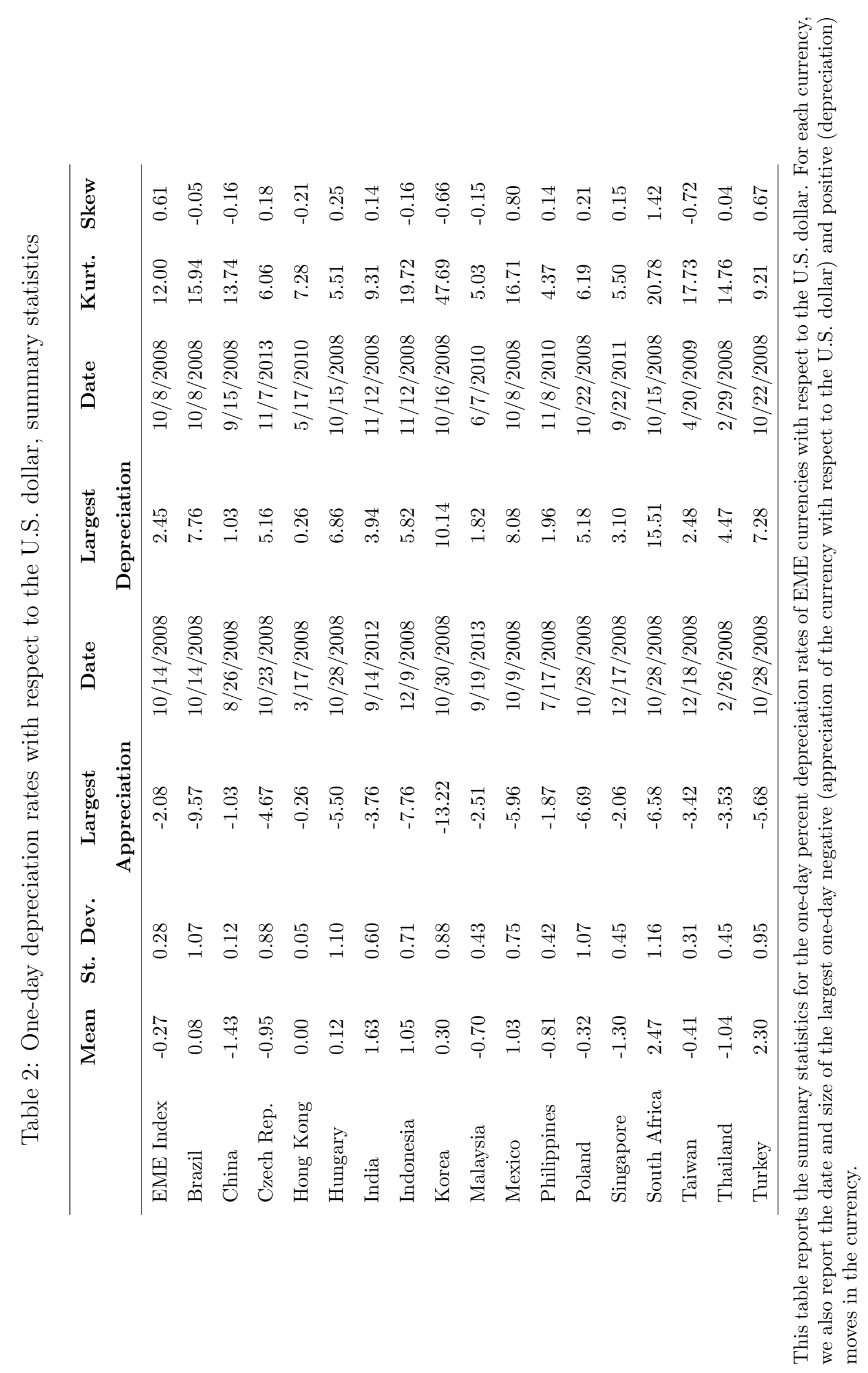




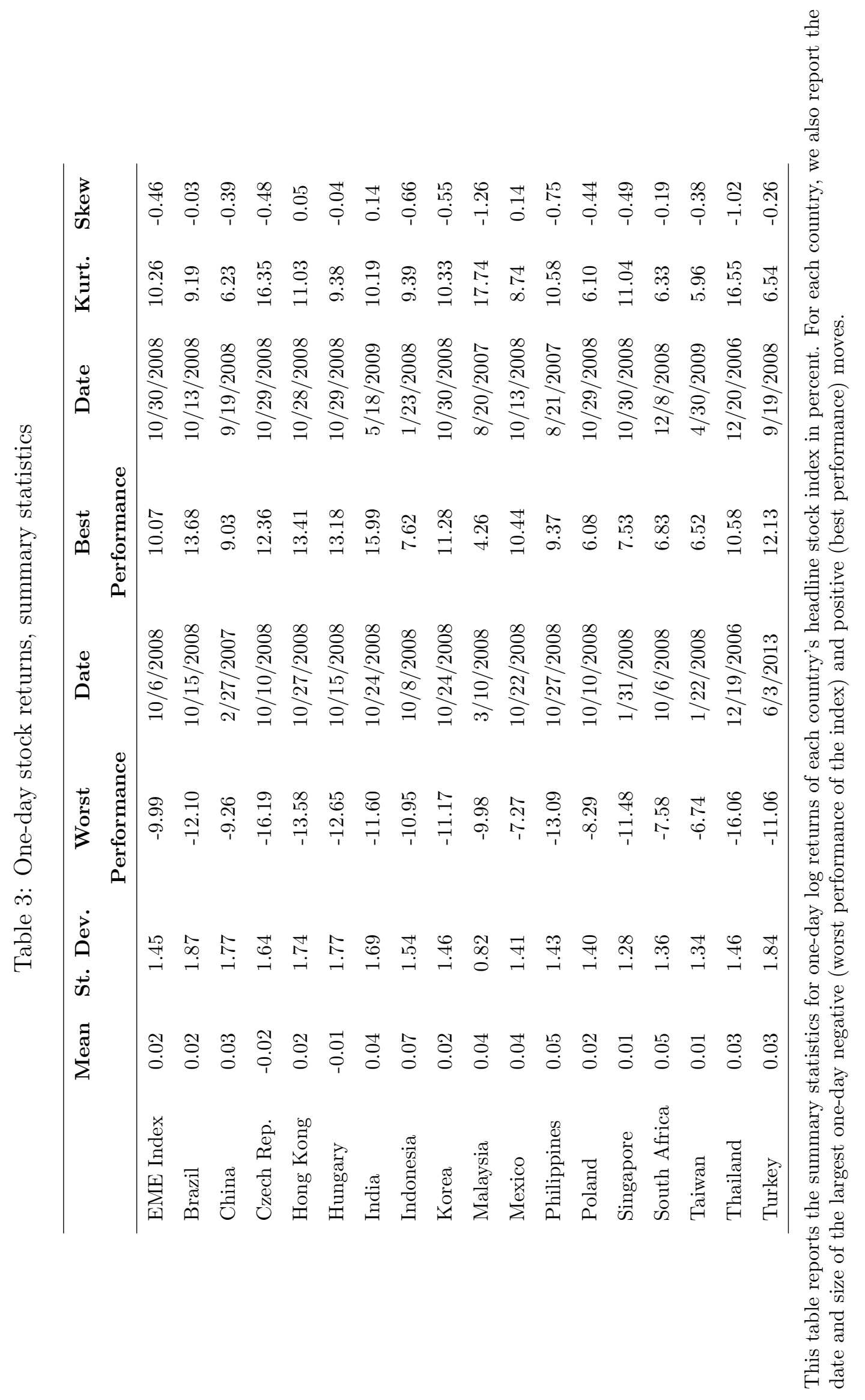




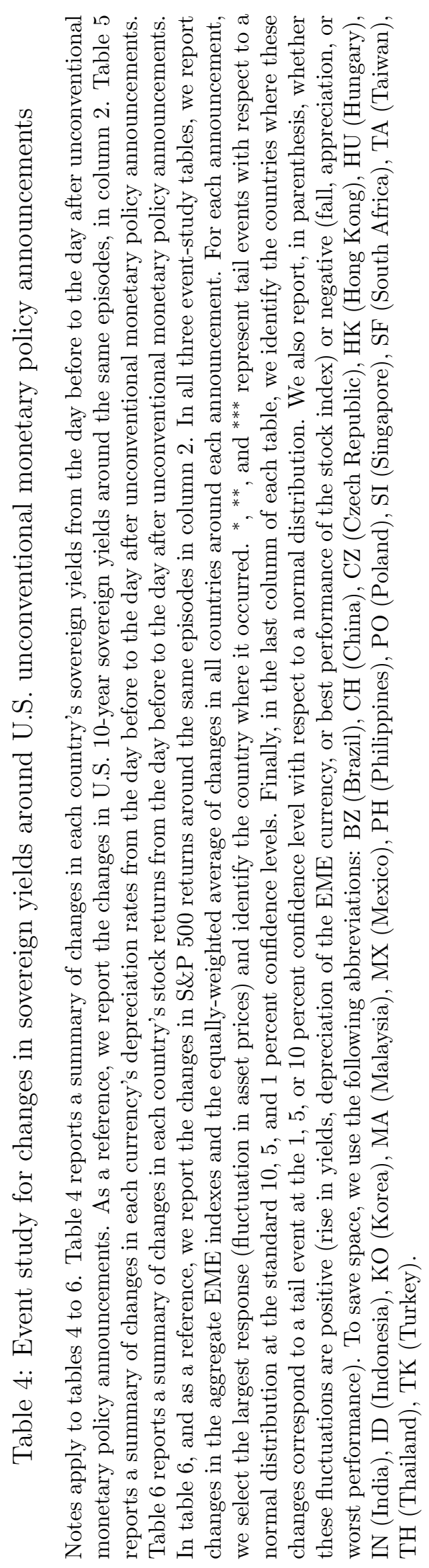




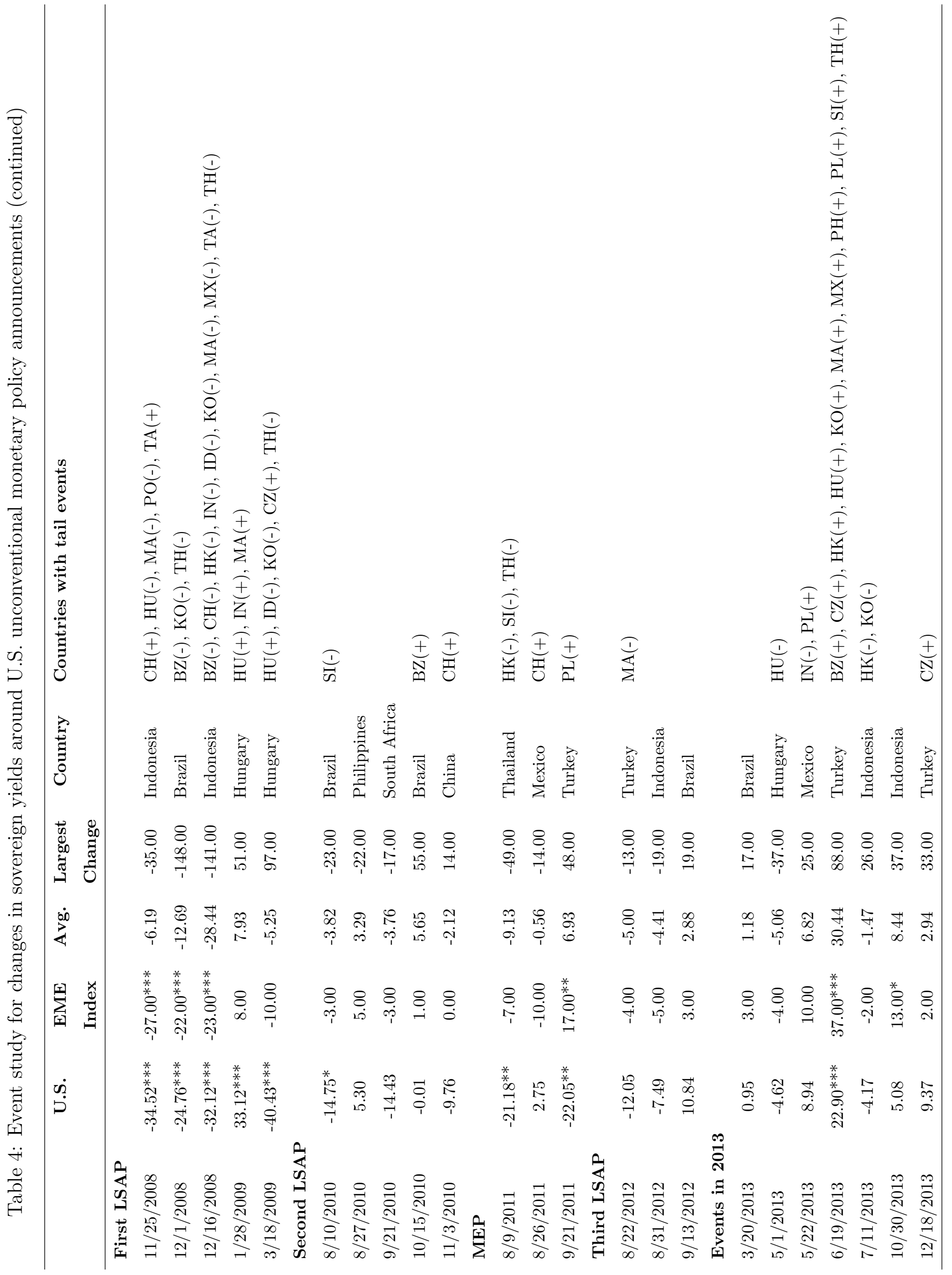




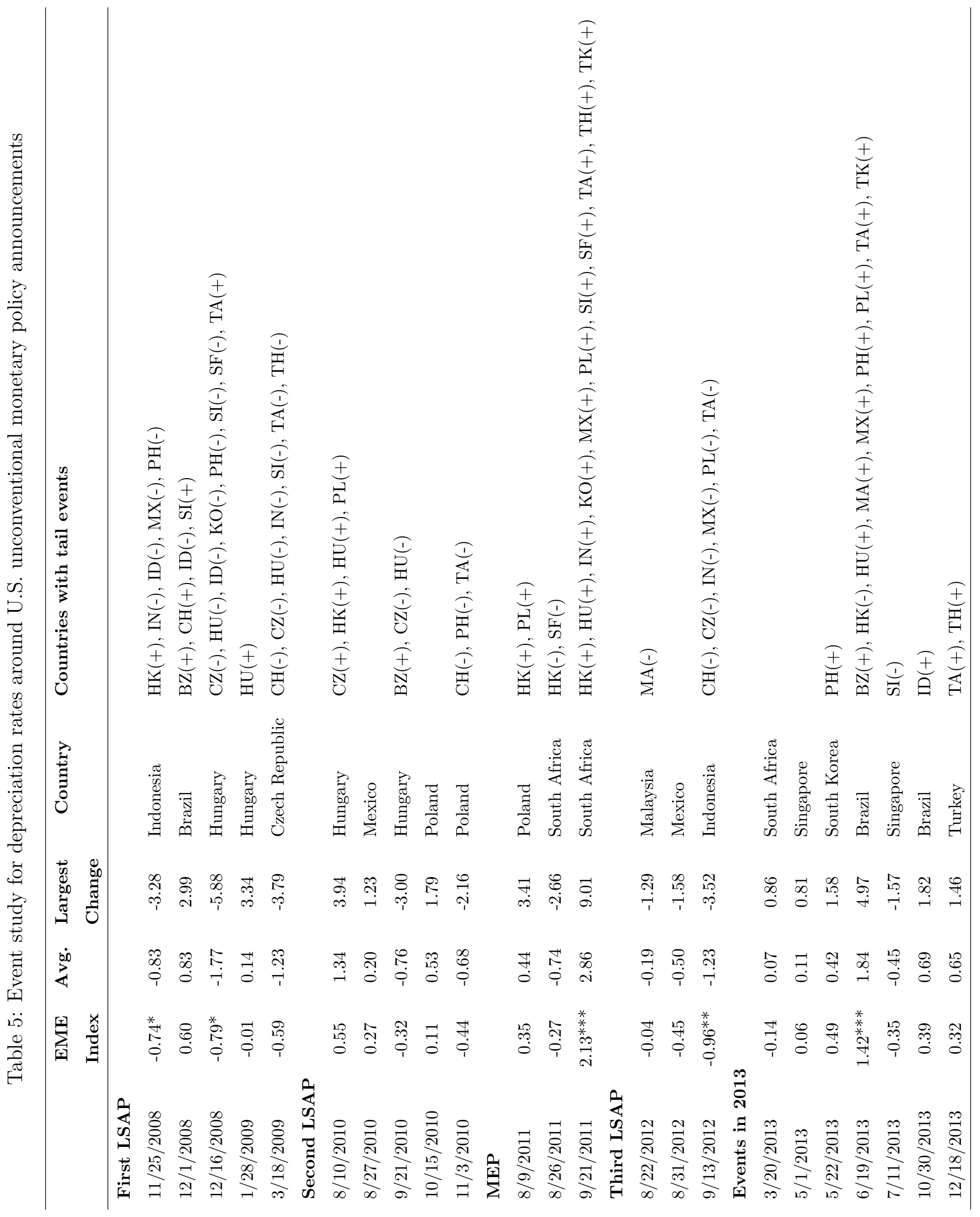




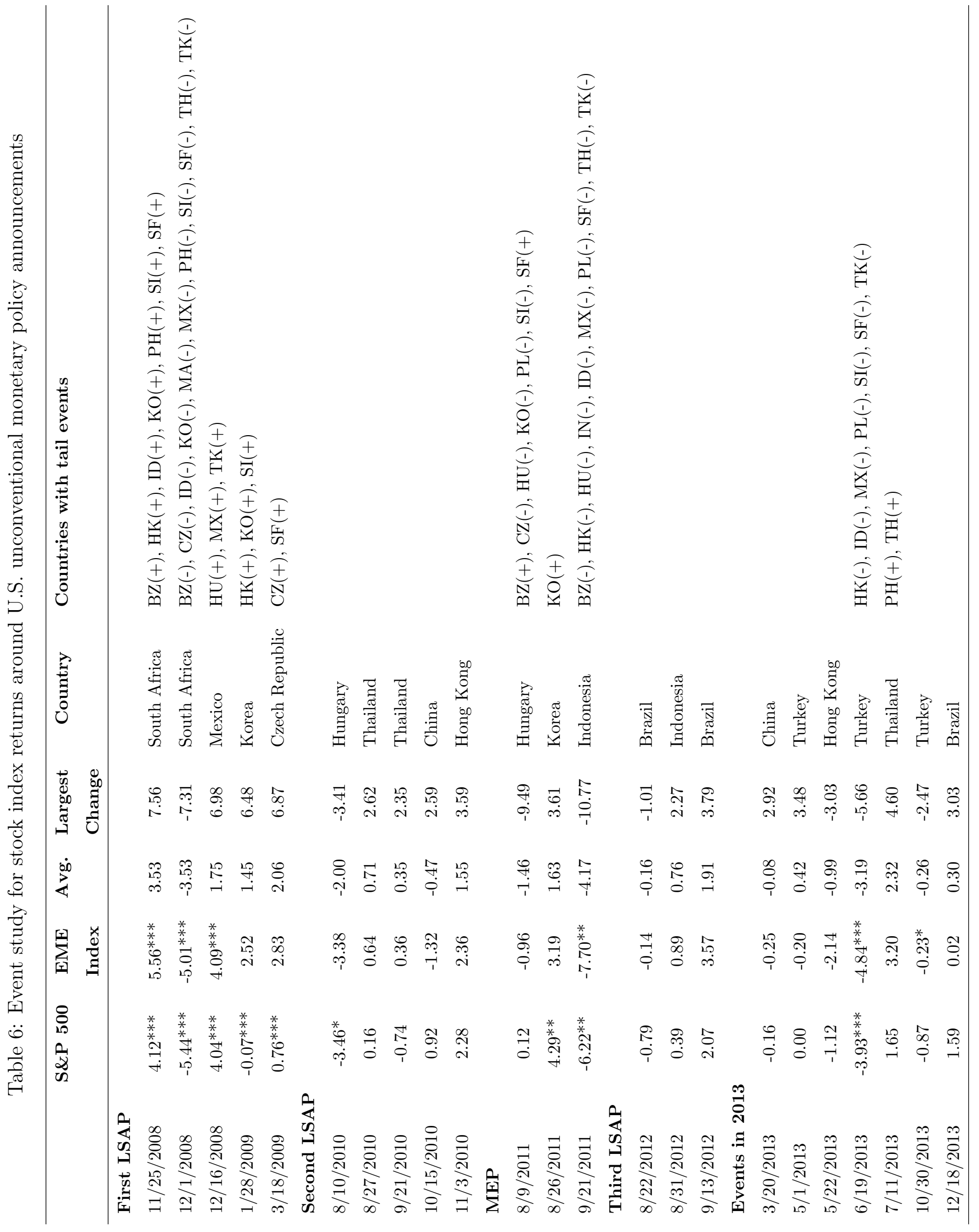


Table 7: Determinants of responses in EME sovereign yields to U.S. financial variables

This table reports the estimated coefficients $\beta_{2}$ and $\gamma_{2}$ in the following panel-data setup:

$$
\Delta Y_{i, t_{m}}^{E M E}=\alpha_{i}+\left(\beta_{1}+\beta_{2} * X_{i, t_{m}-1}\right) * \Delta Y_{\text {sov }, t_{m}}^{U S}+\left(\gamma_{1}+\gamma_{2} * X_{i, t_{m}-1}\right) * \Delta Y_{h y, t_{m}}^{U S}+\mathbf{Z}_{t_{m}}+\epsilon_{i, t_{m}},
$$

where $\Delta Y_{i, t_{m}}^{E M E}$ is the one-month change in sovereign bond yields. $\Delta Y_{\text {sov }}^{U .,_{t_{m}}}$ and $\Delta Y_{h y, t_{m}}^{U . S .}$ are the onemonth changes in 10-year U.S. sovereign yields and high-yield bond spreads, respectively. We allow for the response of each country's asset price to changes in these U.S. financial variables to depend on each country's characteristics, $X_{i, t_{m}-1}$ (see appendix A). We also add a set of control variables, $\mathbf{Z}_{t_{m}}$, including the VIX, a commodity price index, and S\&P 500 returns. ${ }^{*},{ }^{* *}$, and ${ }^{* * *}$ represent significance at the standard 10 , 5 , and 1 percent confidence levels where the standard deviations are corrected by panel-data Newey West. In the last column, we report the gains in R-squared, which is measured as the difference between the $\mathrm{R}$-squared in equation 3 and the R-squared of the same specification without country-specific variables $\left(\Delta Y_{i, t_{m}}^{E M E}=\alpha_{i}+\beta_{1} * \Delta Y_{\text {sov }, t_{m}}^{U S}+\gamma_{1} * \Delta Y_{h y, t_{m}}^{U S}+\mathbf{Z}_{t_{m}}+\epsilon_{i, t_{m}}\right)$.

\begin{tabular}{lrrr}
\hline \multicolumn{1}{c}{ Country } & $\begin{array}{c}\text { U.S. Sovereign } \\
\text { Yield }\end{array}$ & $\begin{array}{r}\text { U.S. High Yield } \\
\text { Spread }\end{array}$ & $\begin{array}{r}\text { Gains in } \\
\mathbf{R}^{2}\end{array}$ \\
\hline Macro/fiscal stability & $0.08^{* *}$ & $0.03^{* * *}$ & 3.26 \\
Policy rate & $0.00^{* * *}$ & $0.00^{* * *}$ & 5.91 \\
CDS & $0.11^{* * *}$ & $0.04^{* * *}$ & 7.51 \\
Gov. yield & $0.11^{* * *}$ & $0.04^{* * *}$ & 8.33 \\
Rate diff. & 0.00 & 0.00 & 0.15 \\
Debt to GDP & 0.10 & 0.08 & 0.50 \\
Inflation & $-0.09^{* * *}$ & $-0.01^{*}$ & 3.06 \\
GDP growth & 0.01 & 0.01 & 0.13 \\
Output gap & 0.01 & & \\
Financial openness/external dependence & $0.01^{* * *}$ & 1.01 \\
-CA/GDP & $-0.27^{* *}$ & -0.01 & 0.82 \\
Financial open. & 0.00 & $0.00^{* * *}$ & 1.09 \\
Market cap. to GDP & 0.00 & $-0.01^{* *}$ & 1.03 \\
U.S. Exp. to GDP & & & \\
Currency-related & $-0.66^{* *}$ & $-0.24^{* * *}$ & \\
Soft peg & -0.45 & $0.04^{* * *}$ & 2.31 \\
Managed floating & -0.07 & $0.06^{* * *}$ & 1.24 \\
Carry-to-risk ratio & $0.03^{* *}$ & $0.01^{* * *}$ & 3.16 \\
Currency IV & & & 3.58 \\
Bank Vulnerability & $0.46^{* * *}$ & $0.14^{* * *}$ & 3.24 \\
Avg. EDF & $-0.09^{* * *}$ & $-0.04^{* * *}$ & \\
Avg. Moody's & & &
\end{tabular}


Table 8: Determinants of responses in EME exchange rates to U.S. financial variables

This table reports the estimated coefficients $\beta_{2}$ and $\gamma_{2}$ in the following panel-data setup:

$$
\Delta Y_{i, t_{m}}^{E M E}=\alpha_{i}+\left(\beta_{1}+\beta_{2} * X_{i, t_{m}-1}\right) * \Delta Y_{\text {sov, } t_{m}}^{U S}+\left(\gamma_{1}+\gamma_{2} * X_{i, t_{m}-1}\right) * \Delta Y_{h y, t_{m}}^{U S}+\mathbf{Z}_{t_{m}}+\epsilon_{i, t_{m}},
$$

where $\Delta Y_{i, t_{m}}^{E M E}$ is the one-month appreciation rate of each EME currency with respect to the U.S. dollar, $\Delta Y_{\text {sov },_{m}}^{U . S \dot{t}_{m}}$ and $\Delta Y_{h y, t_{m}}^{U . S .}$ are the one-month changes in 10-year U.S. sovereign yields and high-yield bond spreads, respectively. We allow for the response of each country's asset price to changes in these U.S. financial variables to depend on each country's characteristics, $X_{i, t_{m}-1}$ (see appendix A). We also add a set of control variables, $\mathbf{Z}_{t_{m}}$, including the VIX, a commodity price index, and the return of the S\&P 500 index. ${ }^{*},{ }^{* *}$, and ${ }^{* * *}$ represent significance at the standard 10,5 , and 1 percent confidence levels where the standard deviations are corrected by panel-data Newey West. In the last column we report the gains in R-squared, which is measured as the difference between the R-squared in equation 4 and the R-squared of the same specification without country-specific variables $\left(\Delta Y_{i, t_{m}}^{E M E}=\alpha_{i}+\beta_{1} * \Delta Y_{\text {sov } t_{m}}^{U S}+\gamma_{1} * \Delta Y_{h y, t_{m}}^{U S}+\mathbf{Z}_{t_{m}}+\epsilon_{i, t_{m}}\right)$.

\begin{tabular}{lrrr}
\hline \multicolumn{1}{c}{ Country } & $\begin{array}{c}\text { U.S. Sovereign } \\
\text { Yield }\end{array}$ & $\begin{array}{r}\text { U.S. High Yield } \\
\text { Spread }\end{array}$ & $\begin{array}{r}\text { Gains in } \\
\mathbf{R}^{2}\end{array}$ \\
\hline Macro/fiscal stability & & $0.10^{* * *}$ & 1.32 \\
Policy rate & 0.00 & $0.00^{* * *}$ & 2.41 \\
CDS & 0.00 & $0.15^{* * *}$ & 3.38 \\
Gov. yield & 0.08 & $0.17^{* * *}$ & 3.96 \\
Rate diff. & 0.01 & 0.01 & 0.22 \\
Debt to GDP & 0.00 & $0.51^{* *}$ & 0.62 \\
Inflation & 0.11 & -0.04 & 0.65 \\
GDP growth & -0.09 & 0.00 & 0.07 \\
Output gap & $0.09^{* *}$ & $0.08^{* * *}$ & 2.90 \\
Financial openness/external dependence & 0.16 & 0.12 \\
-CA/GDP & 0.58 & $0.00^{* * *}$ & 1.56 \\
Financial open. & $0.00^{* * *}$ & $-0.06^{* *}$ & 1.35 \\
Market cap. to GDP & $-0.11^{*}$ & & \\
U.S. Exp. to GDP & & $-1.75^{* * *}$ & \\
Currency-related & -1.50 & $0.04^{* * *}$ & 2.96 \\
Soft peg & -0.20 & $0.74^{* * *}$ & 2.56 \\
Managed floating & $1.11^{* *}$ & $0.07^{* * *}$ & 3.50 \\
Carry-to-risk ratio & 0.06 & & \\
Currency IV & & 0.28 & 0.42 \\
Bank Vulnerability & -0.10 & -0.06 & 0.24 \\
Avg. EDF & & & \\
Avg. Moody's & & & \\
\hline
\end{tabular}


Table 9: Determinants of responses in EME stock prices to U.S. financial variables

This table reports the estimated coefficients $\beta_{2}$ and $\gamma_{2}$ in the following panel-data setup:

$$
\Delta Y_{i, t_{m}}^{E M E}=\alpha_{i}+\left(\beta_{1}+\beta_{2} * X_{i, t_{m}-1}\right) * \Delta Y_{\text {sov }, t_{m}}^{U S}+\left(\gamma_{1}+\gamma_{2} * X_{i, t_{m}-1}\right) * \Delta Y_{h y, t_{m}}^{U S}+\mathbf{Z}_{t_{m}}+\epsilon_{i, t_{m}},
$$

where $\Delta Y_{i, t_{m}}^{E M E}$ is the one-month log return of each EME country's headline stock index, $\Delta Y_{\text {sov }}^{U . \mathrm{t}_{m}}$ and $\Delta Y_{h y, t_{m}}^{U . S .}$ are the one-month changes in 10-year U.S. sovereign yields and high-yield bond spreads, respectively. We allow for the response of each country's asset price to changes in these U.S. financial variables to depend on each country's characteristics, $X_{i, t_{m}-1}$ (see appendix A). We also add a set of control variables, $\mathbf{Z}_{t_{m}}$, including the VIX, a commodity price index, and the return of the S\&P 500 index. ${ }^{*},{ }^{* *}$, and ${ }^{* * *}$ represent significance at the standard 10, 5 , and 1 percent confidence levels where the standard deviations are corrected by panel-data Newey West. In the last column we report the gains in R-squared, which is measured as the difference between the R-squared in equation 5 and the R-squared of the same specification without countryspecific variables $\left(\Delta Y_{i, t_{m}}^{E M E}=\alpha_{i}+\beta_{1} * \Delta Y_{\text {sov } t_{m}}^{U S}+\gamma_{1} * \Delta Y_{h y, t_{m}}^{U S}+\mathbf{Z}_{t_{m}}+\epsilon_{i, t_{m}}\right)$.

\begin{tabular}{lccc}
\hline \multicolumn{1}{c}{ Country } & $\begin{array}{c}\text { U.S. Sovereign } \\
\text { Yield }\end{array}$ & $\begin{array}{c}\text { U.S. High Yield } \\
\text { Spread }\end{array}$ & $\begin{array}{c}\text { Gains in } \\
\mathbf{R}^{2}\end{array}$ \\
\hline Macro/fiscal stability & & & \\
Policy rate & 0.15 & 0.02 & 0.04 \\
CDS & -0.01 & 0.00 & 0.18 \\
Gov. yield & -0.14 & -0.03 & 0.05 \\
Rate diff. & -0.13 & -0.04 & 0.05 \\
Debt to GDP & 0.02 & $-0.01^{*}$ & 0.23 \\
Inflation & 0.21 & -0.26 & 0.05 \\
GDP growth & $0.43^{* * *}$ & -0.04 & 0.69 \\
Output gap & -0.10 & -0.05 & 0.05 \\
Financial openness/external dependence & & \\
-CA/GDP & -0.08 & -0.02 & 0.07 \\
Financial open. & 0.25 & -0.17 & 0.04 \\
Market cap. to GDP & 0.00 & 0.00 & 0.03 \\
U.S. Exp. to GDP & 0.04 & $0.05^{* *}$ & 0.24 \\
Currency-related & & & \\
Soft peg & 0.46 & -0.30 & \\
Managed floating & -1.16 & $0.04^{* * *}$ & 0.31 \\
Carry-to-risk ratio & 0.26 & 0.13 & 0.02 \\
Currency IV & -0.09 & 0.02 & 0.26 \\
Bank Vulnerability & & & \\
Avg. EDF & -0.59 & 0.19 & 0.10 \\
Avg. Moody's & $0.50^{* *}$ & -0.01 & 0.38 \\
\hline
\end{tabular}




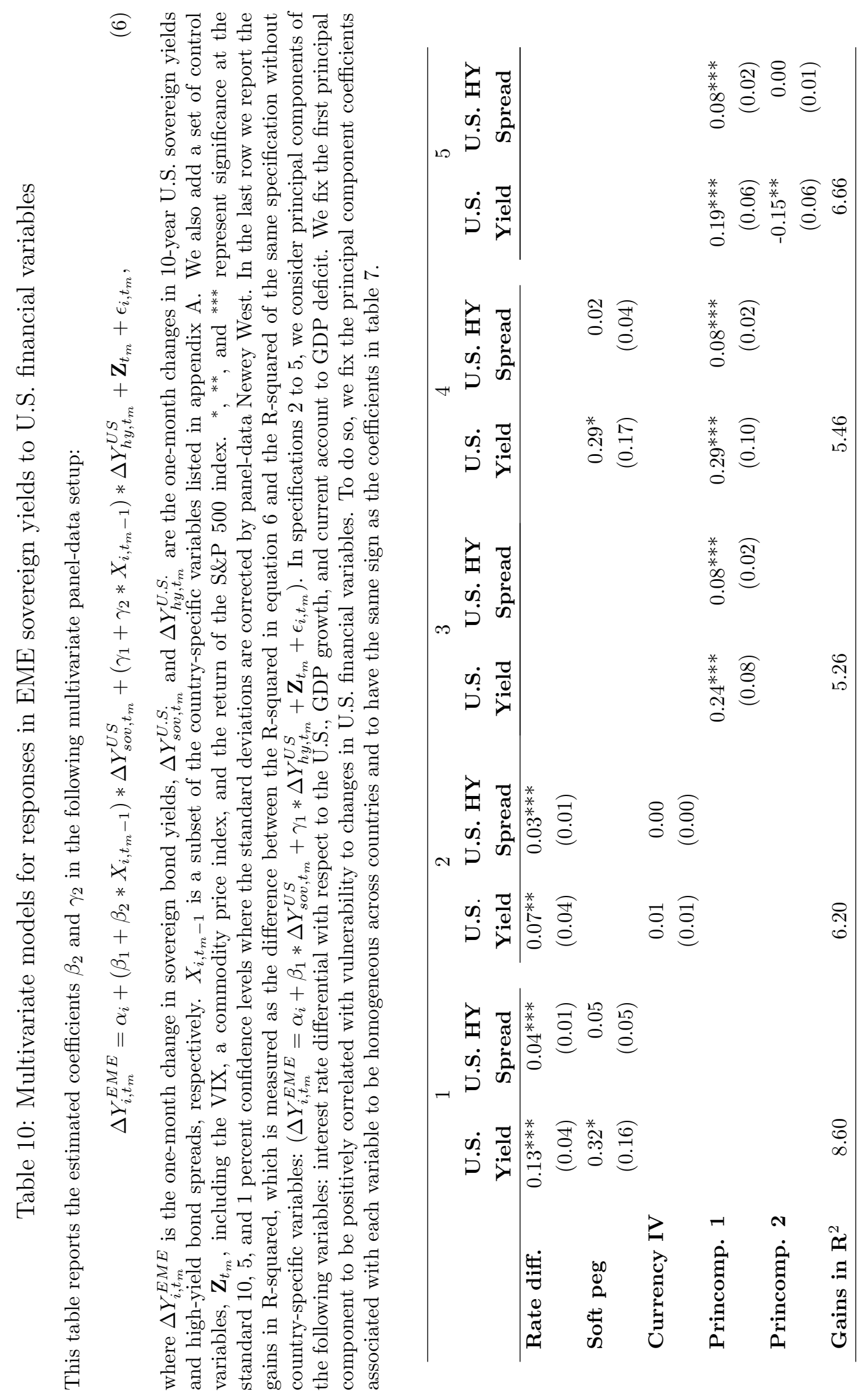




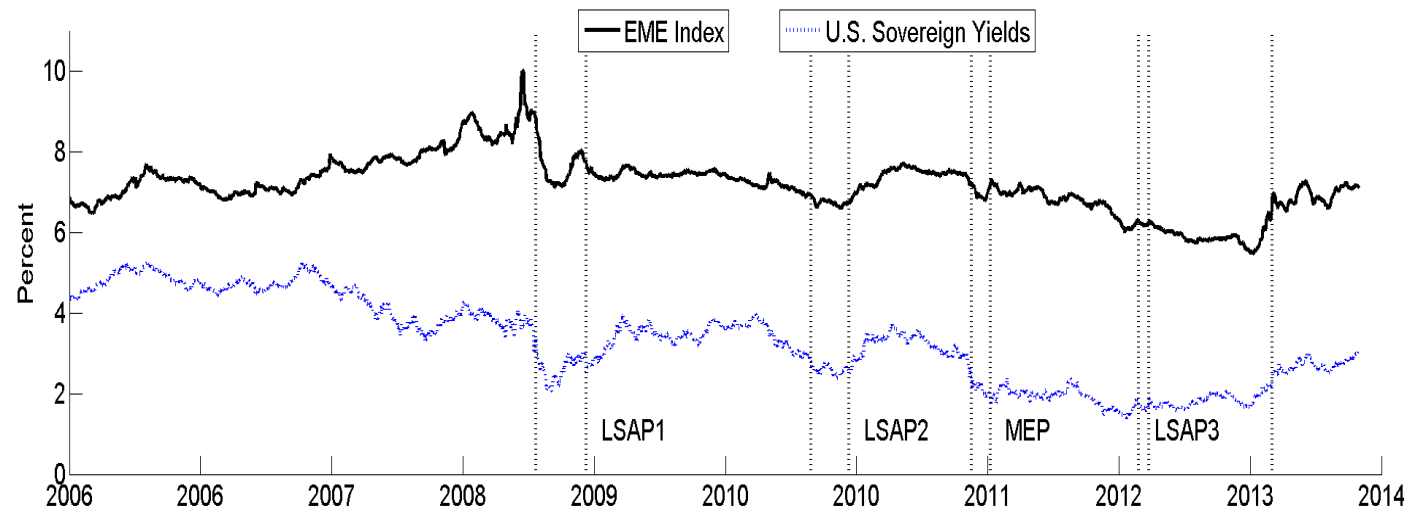

A. EME sovereign yields

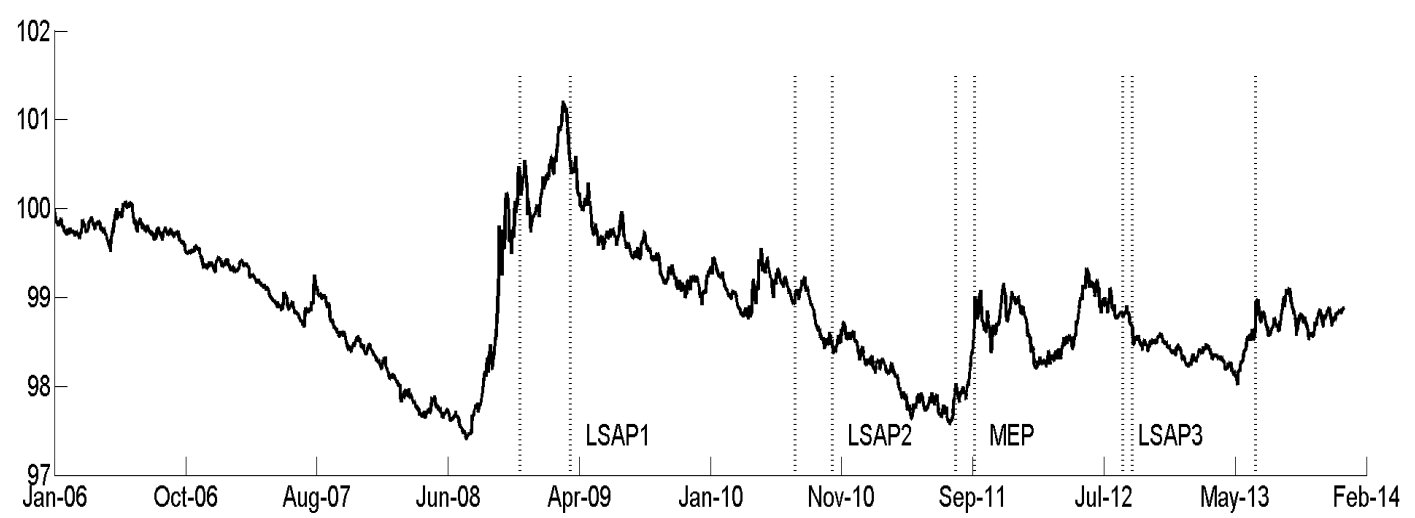

B. EME exchange rates

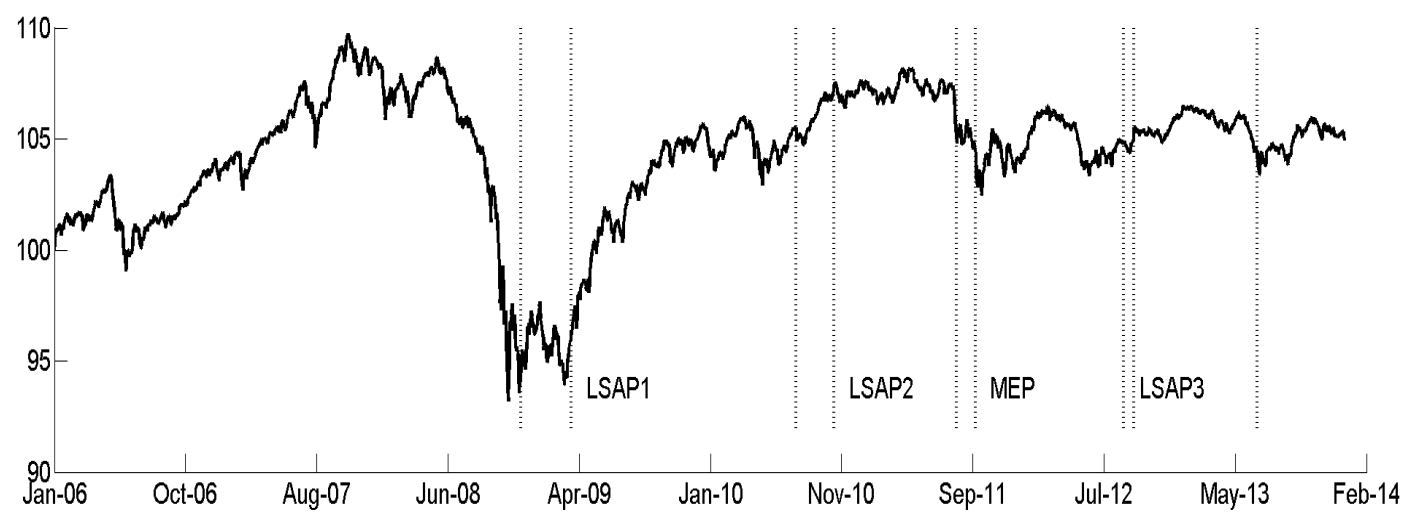

C. EME stock prices

Figure 1: EME asset prices and U.S. sovereign yields

This figure shows the EME aggregate index for sovereign yields (panel A), exchange rate (panel B, indexed at the beginning of the sample), and stock prices (panel C, also indexed). Panel A also shows U.S. 10-year sovereign bond yields. 

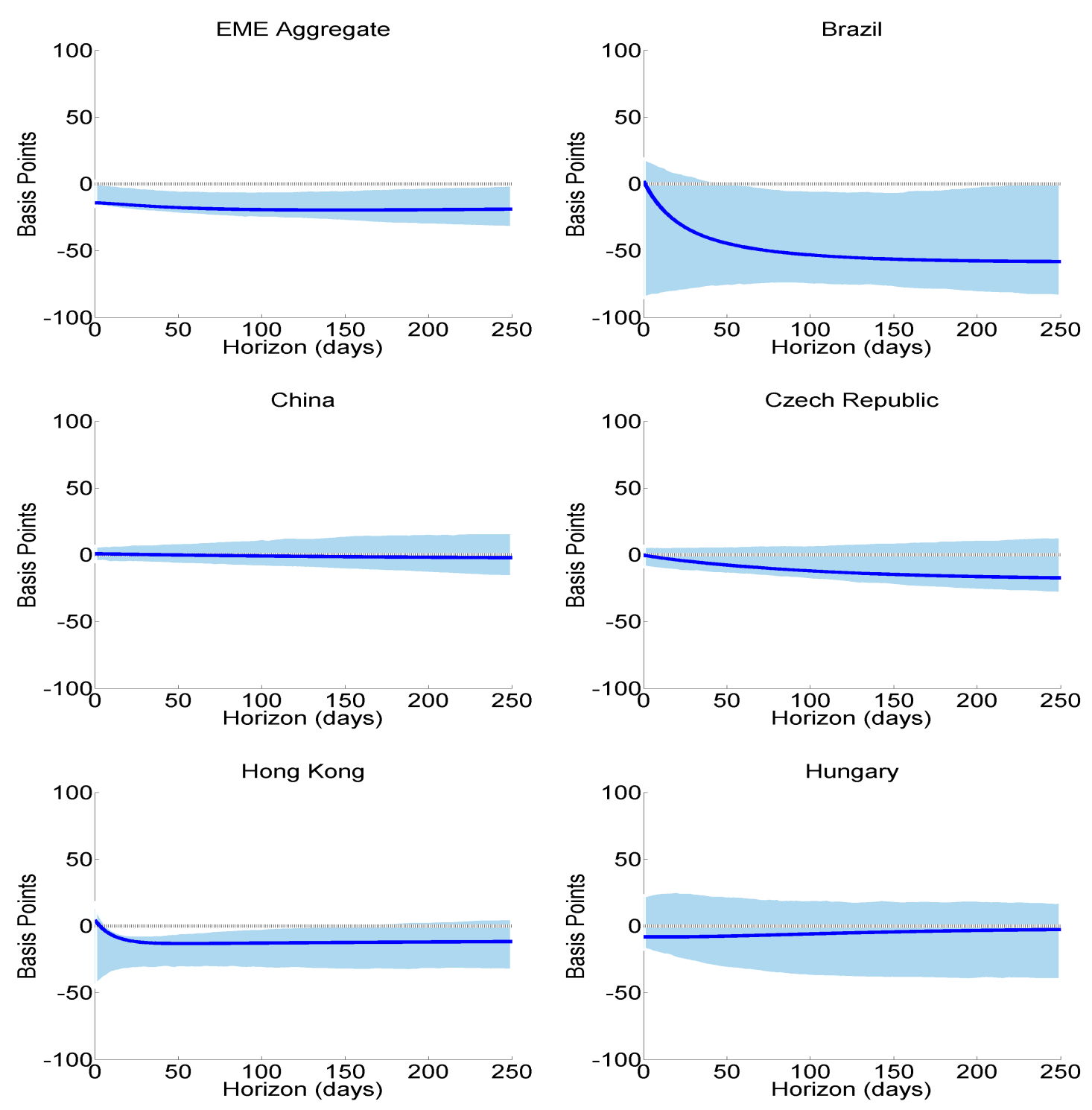

Figure 2: Impulse-response functions. The effect of U.S. monetary policy shocks on EME sovereign yields

This figure shows the estimated effect of a U.S. monetary policy shock that lowers U.S. 10-year sovereign yields by 25 basis points. The effect is estimated on EME sovereign yields over a 250 business day horizon (roughly one year). The estimated effect and the bias-adjusted-bootstrap 90 percent confidence intervals (the dashed lines) are calculated following Wright (2012) as described in the main text. We also report the effect on the EME aggregate index. 

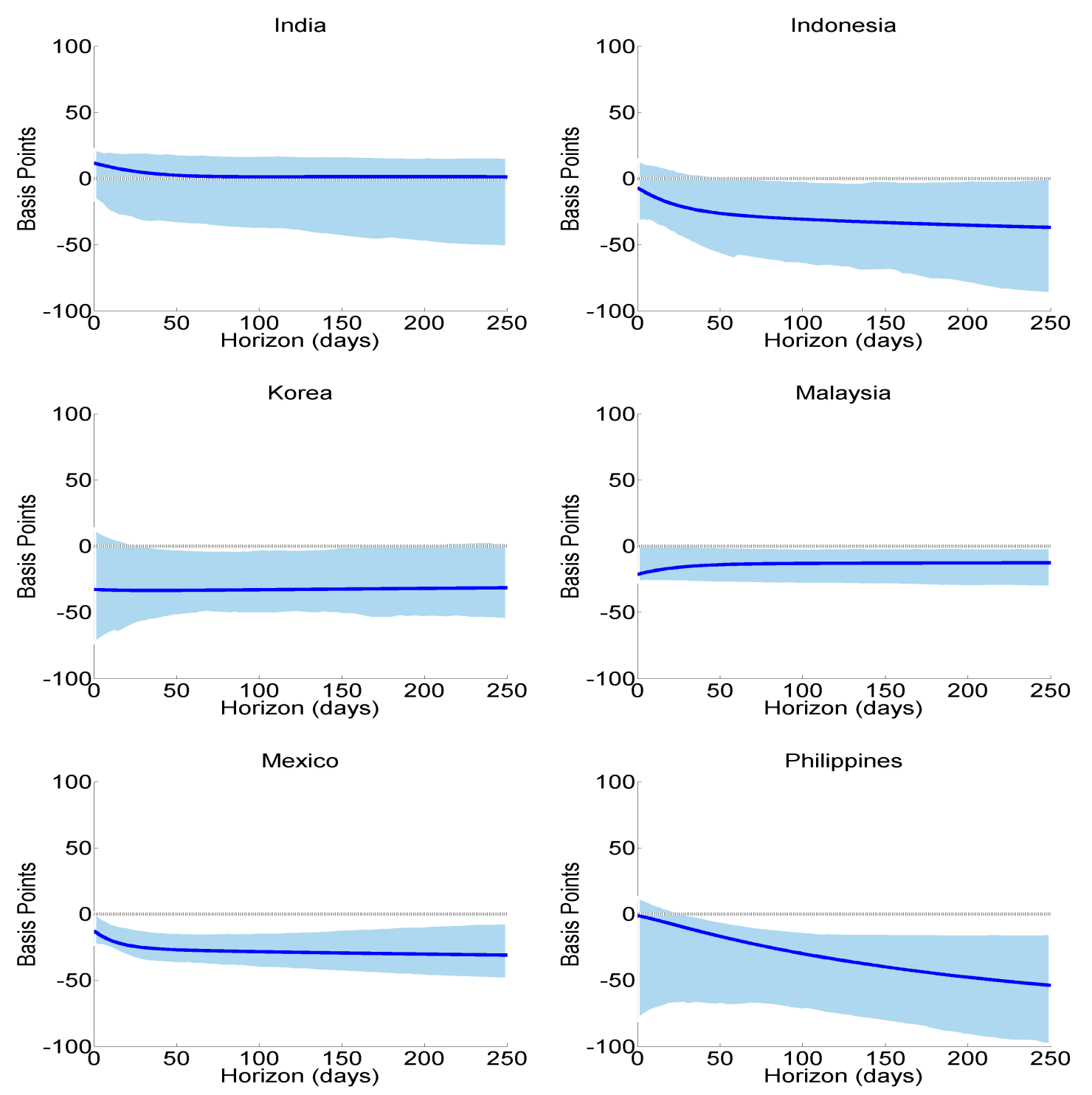

Figure 2: Impulse-response functions. The effect of U.S. monetary policy shocks on EME sovereign yields (continued) 

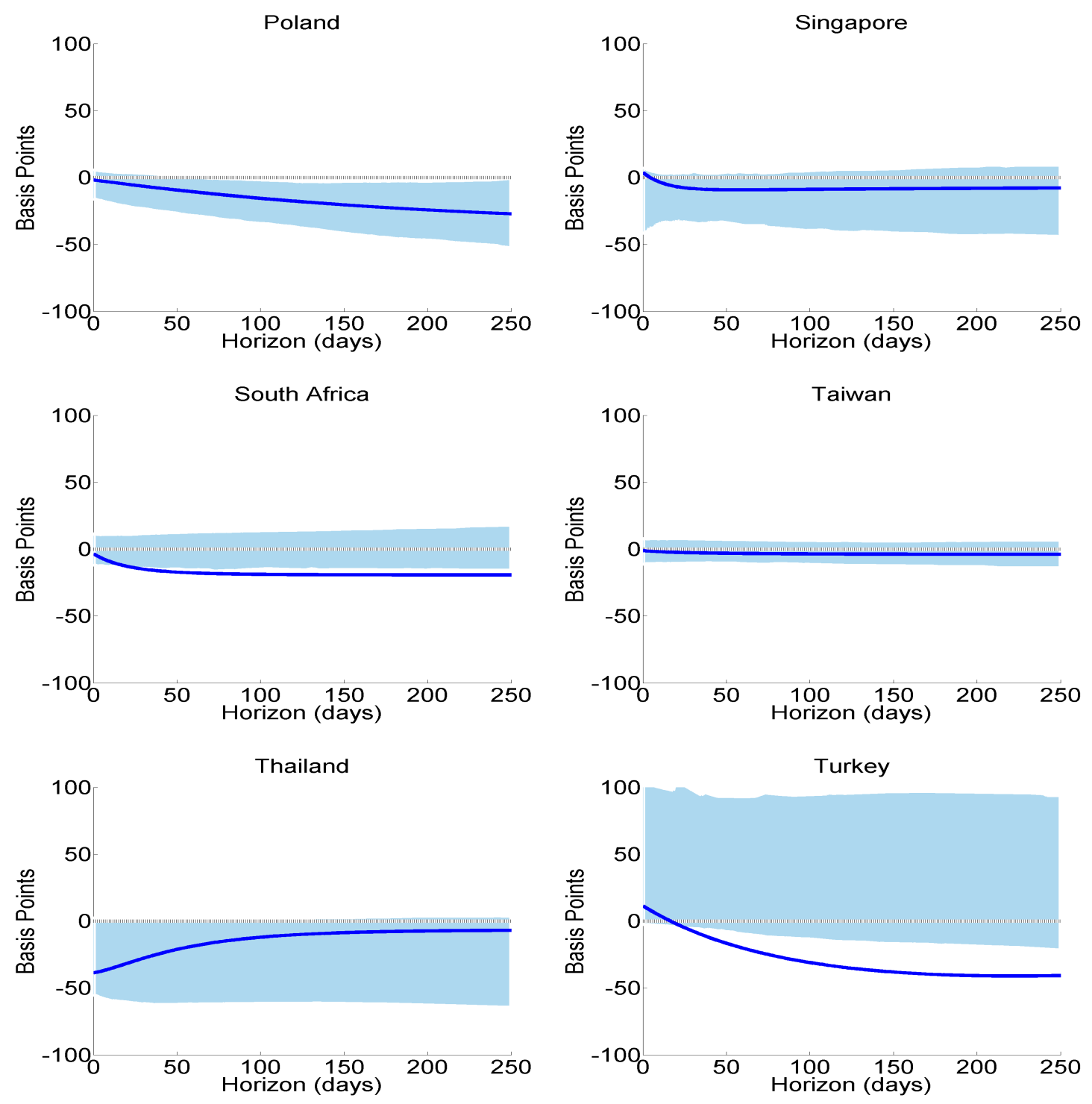

Figure 2: Impulse-response functions. The effect of U.S. monetary policy shocks on EME sovereign yields (continued) 

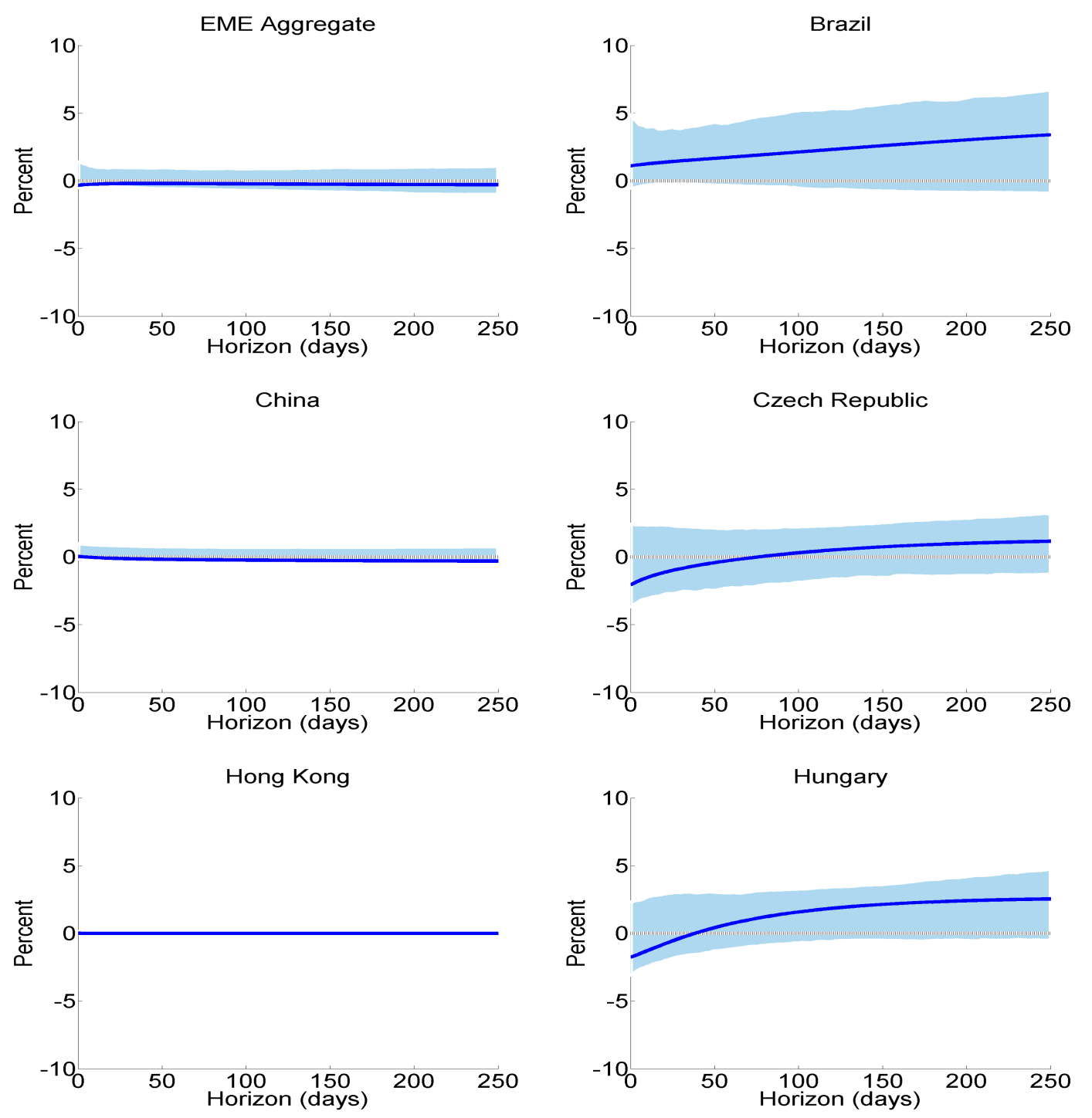

Figure 3: Impulse-response functions. The effect of U.S. monetary policy shocks on EME exchange rates

This figure shows the estimated effect of a U.S. monetary policy shock that lowers U.S. 10-year sovereign yields by 25 basis points. The effect is estimated on EME exchange rates (with respect to the U.S. dollar) over a 250 business day horizon (roughly one year). The estimated effect and the bias-adjusted-bootstrap 90 percent confidence intervals (the dashed lines) are calculated following Wright (2012) as described in the main text. We also report the effect on the EME aggregate index. 

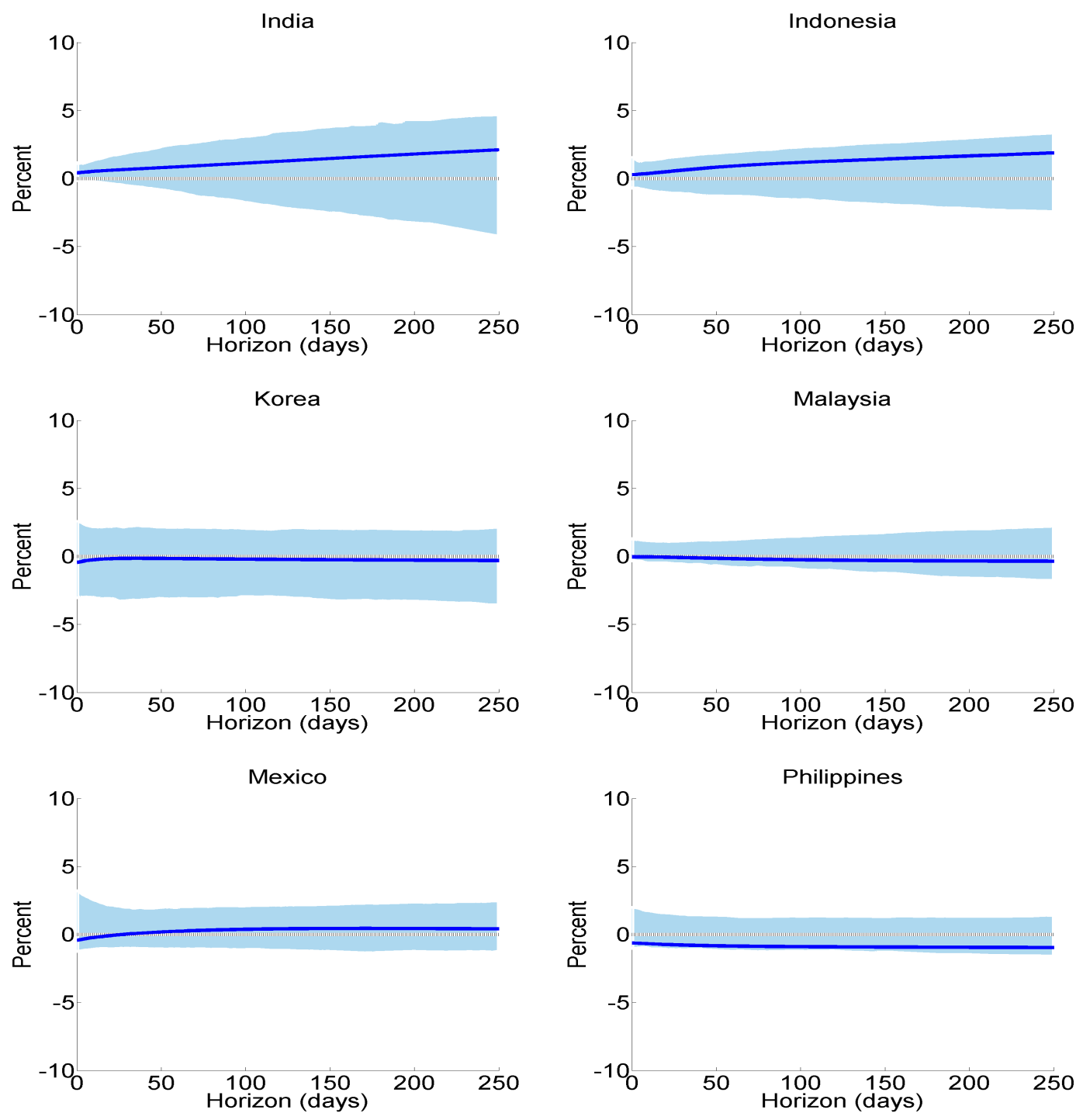

Figure 3: Impulse-response functions. The effect of U.S. monetary policy shocks on EME exchange rates (continued) 

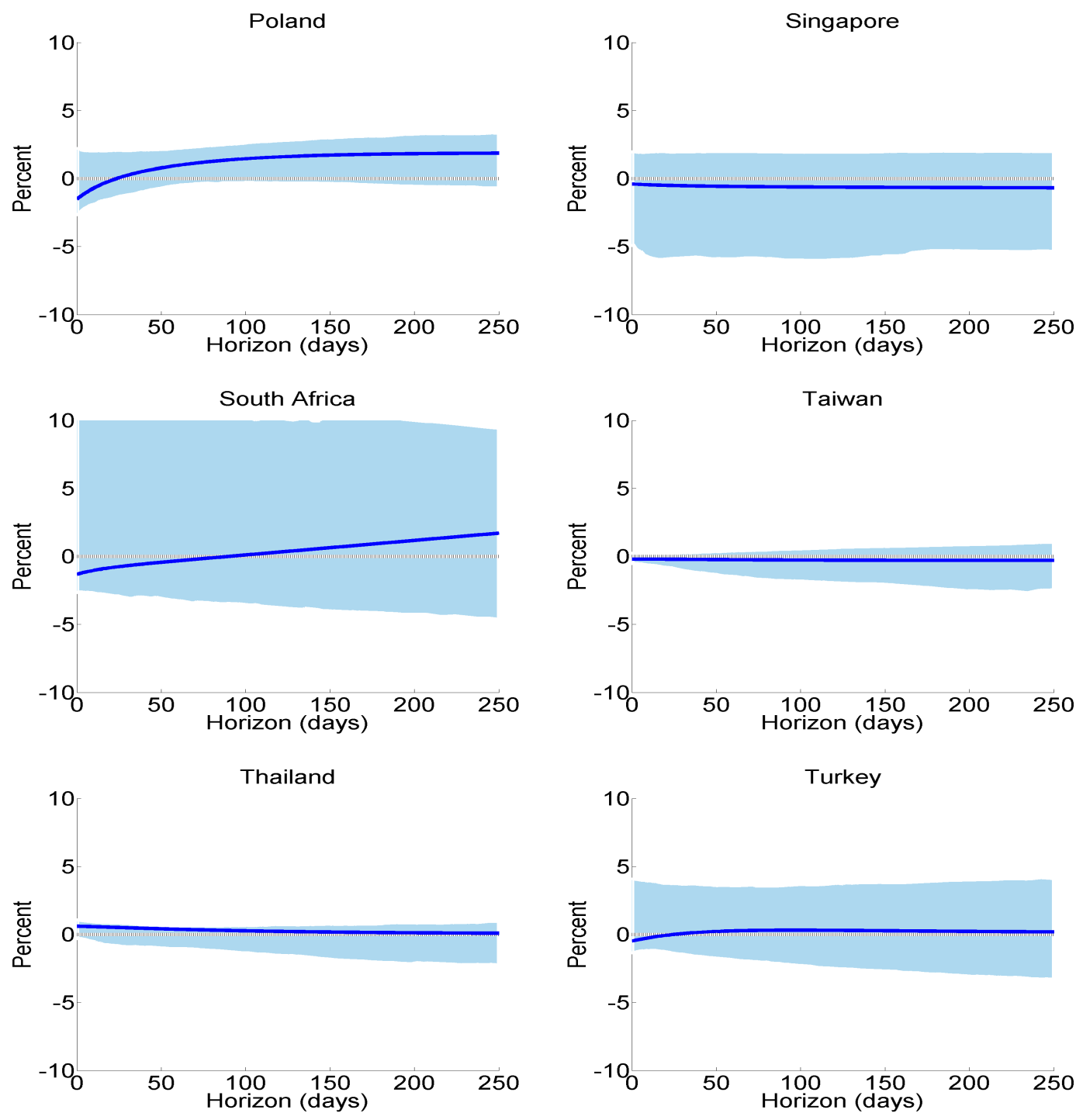

Figure 3: Impulse-response functions. The effect of U.S. monetary policy shocks on EME exchange rates (continued) 

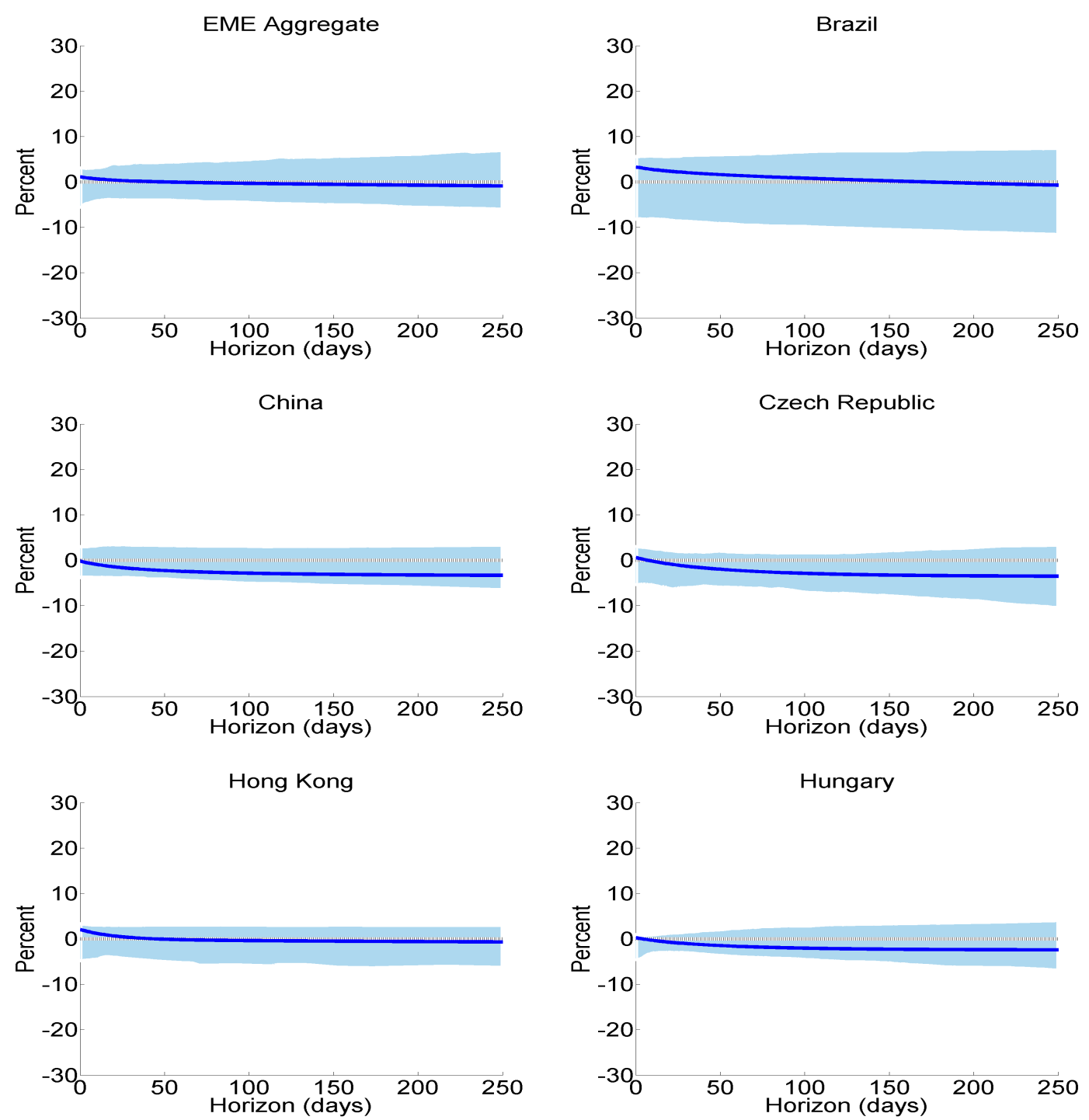

Figure 4: Impulse-response functions. The effect of U.S. monetary policy shocks on EME stock prices.

This figure shows the estimated effect of a U.S. monetary policy shock that lowers U.S. 10-year sovereign yields by 25 basis points. The effect is estimated on EME stock prices over a 250 business day horizon (roughly one year). The estimated effect and the bias-adjusted-bootstrap 90 percent confidence intervals (the dashed lines) are calculated following Wright (2012) as described in the main text. We also report the effect on the EME aggregate index. 

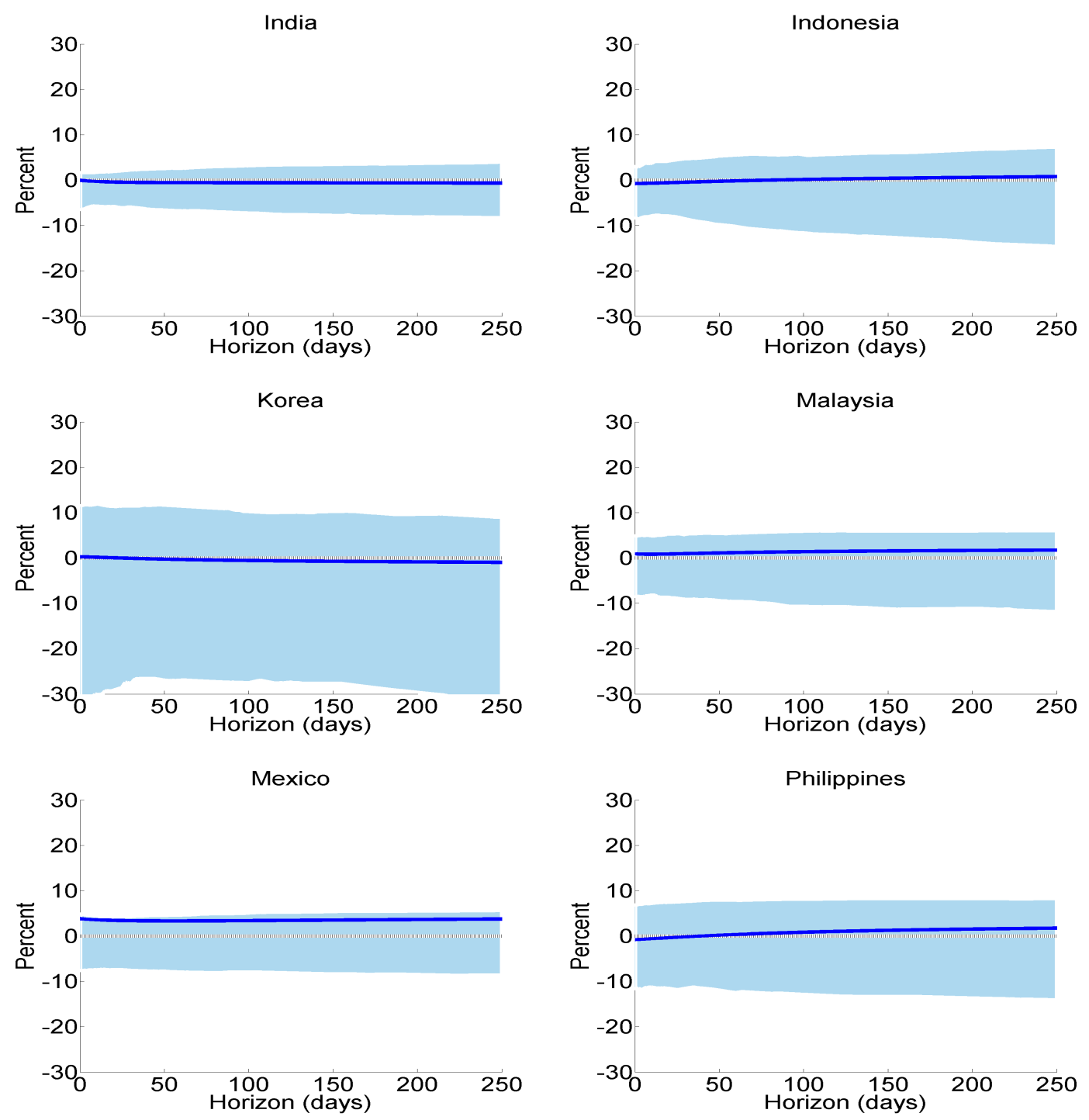

Figure 4: Impulse-response functions. The effect of U.S. monetary policy shocks on EME stock prices (continued) 

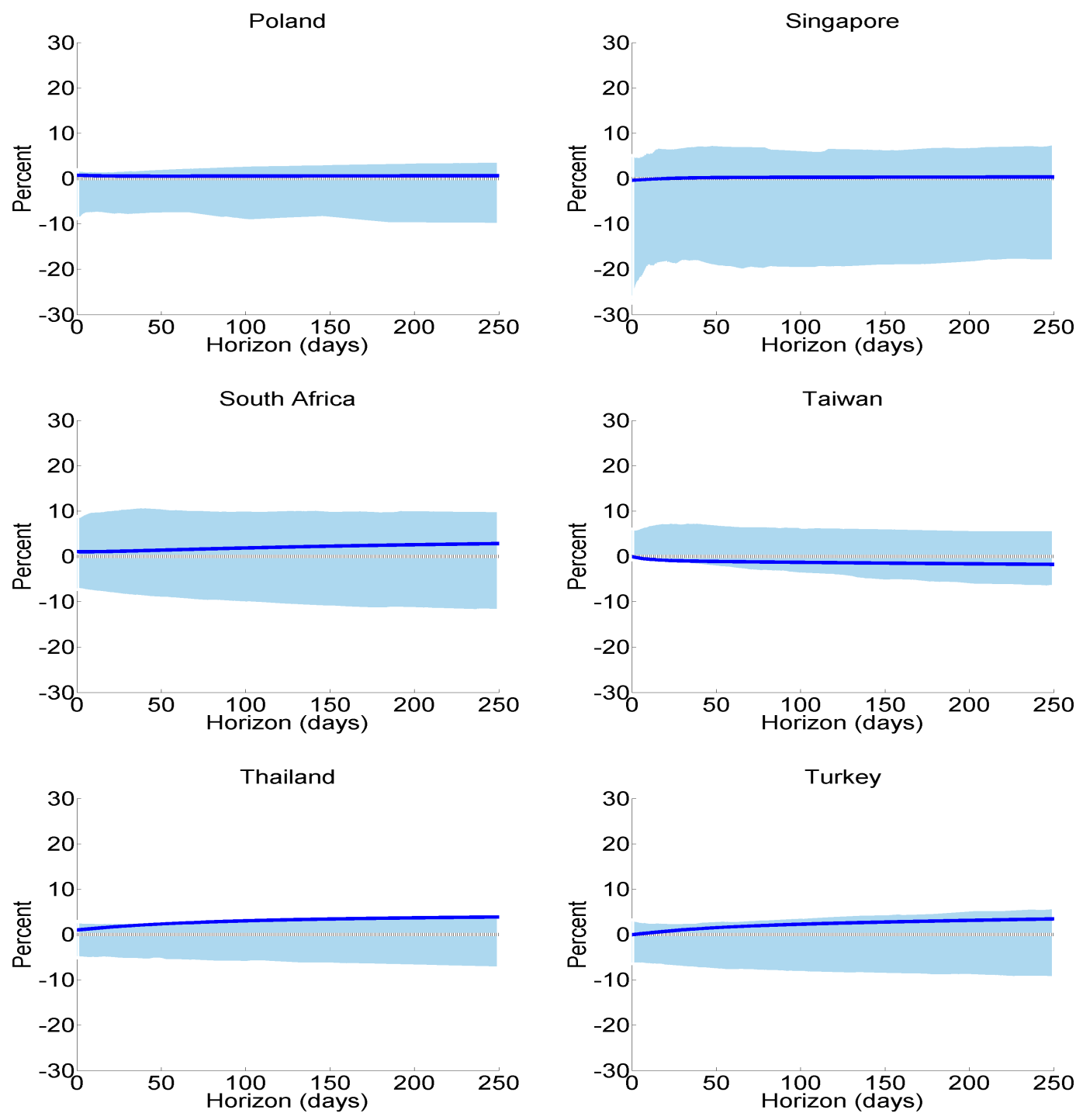

Figure 4: Impulse-response functions. The effect of U.S. monetary policy shocks on EME stock prices (continued) 


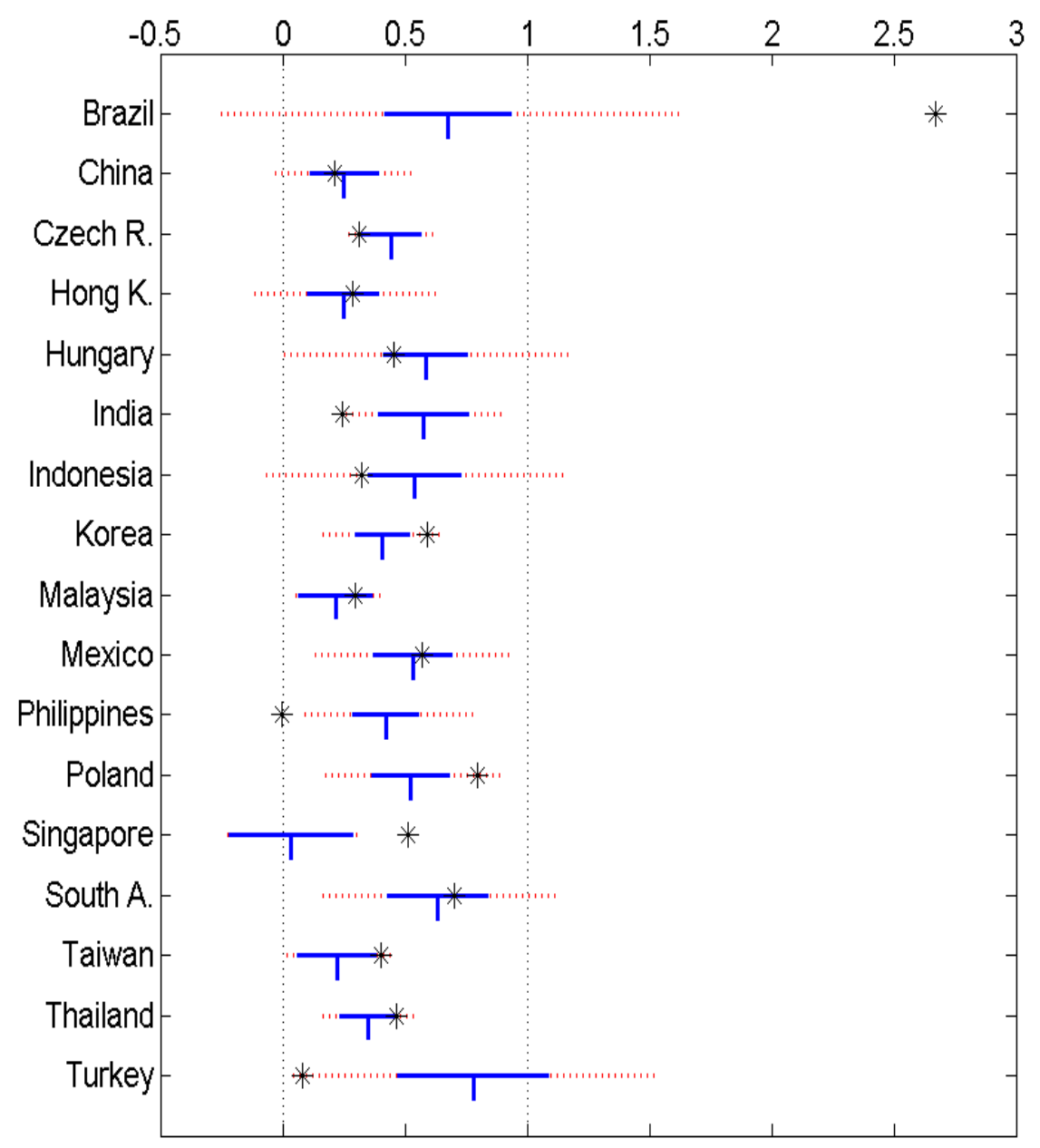

Figure 5: Average model-implied and 2-day observed responses of EME sovereign yields to changes in U.S. Treasury yields

The stars indicate the average observed response (2-day change) of a country's sovereign yields to changes in 10-year U.S. sovereign yields around unconventional monetary policy announcements (in table 4). The bold blue line represents each country's model-implied response (see table 10, specification 1) and its 95 percent confidence interval. The dotted red line represents the augmented 95 percent confidence interval. This augmented interval is calculated using a weighted average of the average model-implied and observed reaction's standard deviation. The standard deviations' weights are based on the number of observations: 23 observed reactions and 1,692 model-implied reactions. 


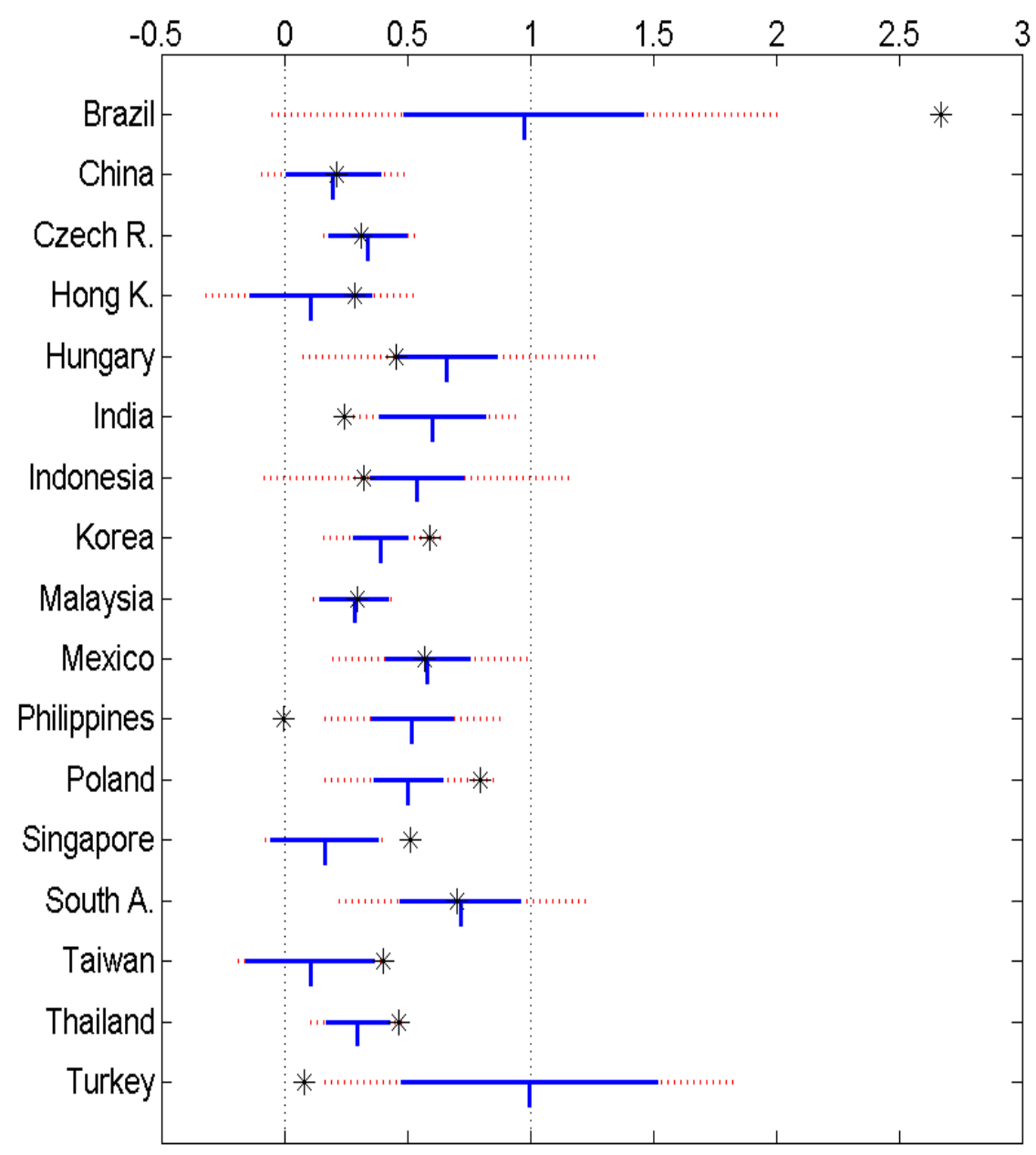

Figure 6: Average model-implied and observed responses of EME sovereign yields to changes in U.S. Treasury yields, panel-data model with currency implied volatility

The stars indicate the average observed response (2-day change) of a country's sovereign yields to changes in 10-year U.S. sovereign yields around unconventional monetary policy announcements (in table 4). The bold blue line represents each country's model-implied response for specification 2 in table 10 and its 95 percent confidence interval. The dotted red line represents the augmented 95 percent confidence interval. This augmented interval is calculated using a weighted average of the average model-implied and observed reaction's standard deviation. The standard deviations' weights are based on the number of observations: 23 observed reactions and 1,692 model-implied reactions. 


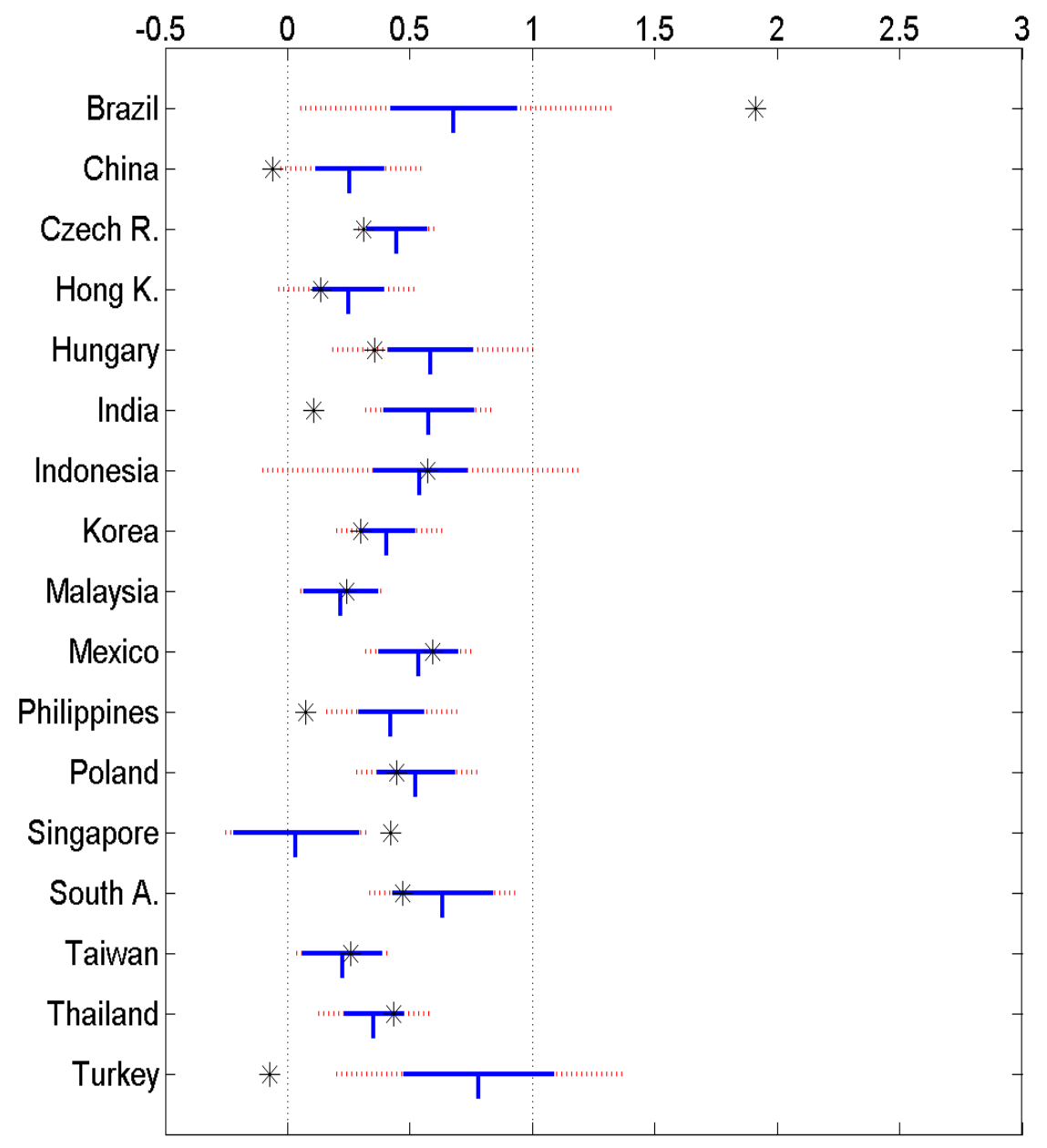

Figure 7: Average model-implied and 1- to 2-day observed responses of EME sovereign yields to changes in U.S. Treasury yields

The stars indicate the average of 1- to 2-day observed responses of a country's sovereign yields to changes in 10-year U.S. sovereign yields around unconventional monetary policy announcements. For each event, the 1- to 2-day observed response is calculated as the average between 1-day responses and 2-day responses. The bold blue line represents each country's model-implied response (see table 10, specification 1) and its 95 percent confidence interval. The dotted red line represents the augmented 95 percent confidence interval. This augmented interval is calculated using a weighted average of the average model-implied and observed reaction's standard deviation. The standard deviations' weights are based on the number of observations: 23 observed reactions and 1,692 model-implied reactions. 